\title{
An Approximate Solution for Predicting the Heat Extraction and Preventing Heat Loss from a Closed-Loop Geothermal Reservoir
}

\author{
Bisheng Wu, ${ }^{1}$ Tianshou Ma, ${ }^{2,3}$ Guanhong Feng, ${ }^{4}$ Zuorong Chen, ${ }^{1}$ and Xi Zhang ${ }^{1}$ \\ ${ }^{1}$ CSIRO Energy, 71 Normanby Road, Clayton, VIC 3168, Australia \\ ${ }^{2}$ State Key Laboratory of Oil \& Gas Reservoir Geology and Exploitation, Southwest Petroleum University, \\ Chengdu, Sichuan 610500, China \\ ${ }^{3}$ State Key Laboratory of Geomechanics and Geotechnical Engineering, Institute of Rock and Soil Mechanics, \\ Chinese Academy of Sciences (CAS), Wuhan, Hubei 430071, China \\ ${ }^{4}$ Key Laboratory of Groundwater Resources and Environment, Jilin University, Changchun 130021, China \\ Correspondence should be addressed to Bisheng Wu; bisheng.wu@csiro.au and Tianshou Ma; matianshou@126.com
}

Received 1 April 2017; Revised 5 June 2017; Accepted 19 June 2017; Published 16 August 2017

Academic Editor: Weon Shik Han

Copyright ( 2017 Bisheng Wu et al. This is an open access article distributed under the Creative Commons Attribution License, which permits unrestricted use, distribution, and reproduction in any medium, provided the original work is properly cited.

\begin{abstract}
Approximate solutions are found for a mathematical model developed to predict the heat extraction from a closed-loop geothermal system which consists of two vertical wells (one for injection and the other for production) and one horizontal well which connects the two vertical wells. Based on the feature of slow heat conduction in rock formation, the fluid flow in the well is divided into three stages, that is, in the injection, horizontal, and production wells. The output temperature of each stage is regarded as the input of the next stage. The results from the present model are compared with those obtained from numerical simulator TOUGH2 and show first-order agreement with a temperature difference less than $4^{\circ} \mathrm{C}$ for the case where the fluid circulated for 2.74 years. In the end, a parametric study shows that (1) the injection rate plays dominant role in affecting the output performance, (2) higher injection temperature produces larger output temperature but decreases the total heat extracted given a specific time, (3) the output performance of geothermal reservoir is insensitive to fluid viscosity, and (4) there exists a critical point that indicates if the fluid releases heat into or absorbs heat from the surrounding formation.
\end{abstract}

\section{Introduction}

With the rapid increasing demand for clean and renewable energy, geothermal energy has become one of the most promising alternatives for energy supplies due to its many advantages. First, geothermal energy is inexhaustible and renewable due to radioactive decay from below the earth [1] and there is a wide range of geothermal resources in the world including in the USA, Mexico, Germany, Italy, Finland, Norway, Iceland, Sweden, New Zealand, Australia, Indonesia, and China $[1,2]$. Second, geothermal energy is much cleaner and environmentally friendly compared to the conventional fossil fuels. It has been reported that the geothermal energy based plants produce $1 / 12$ carbon dioxide of the coal based plant [3]; Third, up to date, as only small amount of geothermal resource has been utilized for heating or power generation compared to its large reserve, there is a large potential for extraction.

Closed-loop geothermal system represents an important mean to extract heat from below the earth and study on maximizing its output performance is very important $[4,5]$. The basic principle of a closed-loop system is simple: a cold fluid $\left(\mathrm{CO}_{2}\right.$ or water) is injected into the well, absorbs heat from hotter surrounding rocks when flowing in a channel such as wellbore or fracture, and then is pumped out from the production well. In the present paper, the connecting channel is chosen to be a wellbore. In addition to extracting heat from the reservoir by fluid circulation, the closed-loop system can prevent contaminants in fluids from leaking into the reservoir. As the output performance, including temperature 
and thermal power, of a geothermal reservoir is affected by many factors such as number and location of wells and fractures, flow rates, and velocity and direction of areal flow $[6,7]$, an efficient mathematical model is required for studying the relationship between reservoir performance and these parameters depending on specific system configuration.

Fluid flow and heat transfer in a wellbore/pipe have received a great deal of attention during the last several decades due to their importance in oil and gas industry. For example, the thermoelastic stress change is significant near the wellbore; it may change the fracture initiation and path during hydraulic fracturing [10-12]. The mathematical models can be mainly classified into two types, that is, analytical and numerical. Many studies belong to the first type. For example, Bullard [13] and Moss and White [14] used a line/source model to study the time for a wellbore to attain temperature equilibrium and the temperature evolution in a water-injection well, respectively. Recently, the infinite, cylindrical, and finite line source theories [15] have been widely used for geothermal simulation. For example, Eskilson [16], Zeng et al. [17], Sutton et al. [18], Bandos et al. [19], Michopoulos and Kyriakis [20], Molina-Giraldo et al. [21], HechtMéndez et al. [4], Rivera et al. [22], and Zhou et al. [23] used line source models to predict the temperature evolution in the ground source heat pumps. In addition, Ramey [24] presented approximate solutions for the wellbore/reservoir (W/R) system involved in injection of hot or cold fluid. Dowdle and Cobb [25] applied the Horner temperature plot method, which is similar to conventional pressure build-up, to predict the static wellbore temperature from well logs. Edwardson et al. [26] and Tragesser et al. [27] studied the wellbore temperature during mud circulation by using an exact method which is based on the solution of differential equation of heat conduction. Because the above models do not consider the heat exchange between the fluid inside and that outside the drill pipe, they cannot be used as a general tool for predicting the thermal behaviour in a wellbore/reservoir systems.

As for fluid circulation in a wellbore/reservoir system, the work by Raymond has to be mentioned [28]. In addition to providing systematic derivation of the governing equations characterizing the transient fluid flow and heat transfer, Raymond [28] obtained the analytical solutions for the case with steady state heat transfer in the wellbore by using Laplace transformation and also numerically solved the problem with transient heat transfer in both wellbore and formation by using the finite difference method (FDM). Most of the models studied later on fluid circulation in a wellbore/reservoir system more or less borrow some concepts from Raymond's work [28]. For example, Holmes and Swift [29] solved approximately similar governing equations under assumption of steady state heat transfer between the annular fluid and the formation. Keller et al. [30] considered the effects of heat generated by fluid friction, sliding casing strings, and other energy sources in the system. García et al. [31], EspinosaParedes et al. [32], Fomin et al. [33], and Izgec et al. [34] presented a fully transient FDM model by considering the transient heat behaviour during fluid circulation in a W/R system. Wu et al. [35] solved analytically the transient heat transfer both in the wellbore and formation during drilling with fluid circulation in the wellbore.

In addition to the above-mentioned approaches, recently a large number of numerical open sources or commercial software are available for geothermal simulation. For example, HYDROTHERM by US Geological Survey [36] and TOUGH 2 by Lawrence Berkeley National Laboratory [37] based on FDM, OpenGeoSys by Helmholtz Centre of Environmental Research, Germany [38], ROCKFLOW by Kolditz et al. [39], FEFLOW by Diersch et al. [40, 41], FEHM by Los Alamos National Laboratory [42] and COMSOL [43] based on finite element method (FEM), ECLIPSE by Schlumberger [44], and Fluent by ANSYS [45] based on finite volume method (FVM) have been applied successfully to model the heat extraction from geothermal reservoirs with complicated geometries. In addition, the boundary element method (BEM) was also used for modelling similar problems. For example, Ding [46], Ghassemi et al. [47], Kumar and Gutierrez [48], and McClure and Horne [49] used the BEM or displacement discontinuity element method (DDM) to simulate the heat and mass transfer in geothermal reservoir with single fracture or fracture networks.

Although the above numerical methods can be used to solve complex problems, they sometimes are computationally costly. The analytical methods cannot be directly used to solve the present closed-loop geothermal model because of the complex model geometry. This is the main motivation for carrying out the present work.

The objective of the present work is to provide an approximate approach to predict the heat extraction and thermal power from a closed-loop geothermal reservoir. This paper is organized as follows: in Section 2, the problem description and formulation, including governing equations and boundary and initial conditions, are presented; Section 3 provides the dimensionless formulation, followed by solution method in Section 4. The model validation and numerical results are given in Section 5 and conclusions are presented in Section 6.

\section{Problem Formulation}

2.1. Problem Description and Assumptions. The model geometry studied is shown in Figure 1. It contains one simplified well containing two vertical parts and one horizontal part. The initial temperature of the system is a function of depth; that is, $T_{0}=A_{0} z+B_{0}$, where $A_{0}$ is the geothermal gradient and $B_{0}$ is the surface ground temperature. At time $t>0$, a fluid (water) with a constant temperature $T_{\text {in }}$ is injected into the system at a constant volumetric rate $Q_{1}$. The geometrical sizes of the wellbore shown in Figure 1 are defined as follows: the lengths of the injection, horizontal, and production well sections are $L_{1}, L_{2}$, and $L_{3}\left(L_{3}=L_{1}\right)$, respectively; the radius of the wellbore is $r_{h i}(i=1,2,3)$, possibly including all layers such as steel casing and cementation if they exist as shown in Figure 1. The origin of the general coordinate system (GCS), denoted by the coordinates $(x, y, z)$, is located at the injection point of the vertical well and coincides with the origin of the local cylindrical coordinate system (LCCS), denoted by the coordinate $\left(r_{1}, z\right)$, for the injection well. The 


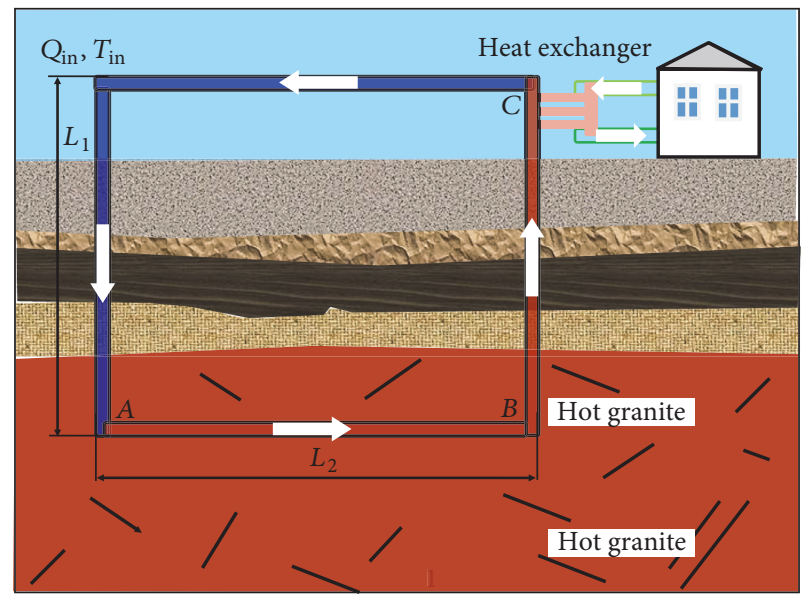

(a)

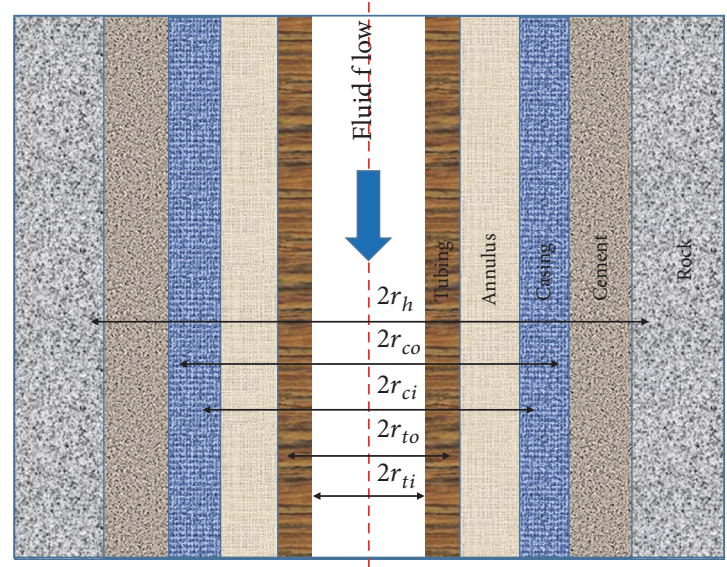

(b)

FIgURE 1: Model geometry. (a) Injection well system and (b) cross section of the well system.

origin of the LCCS, denoted by the coordinate $\left(r_{2}, x\right)$, for the horizontal well is at the bottom of the injection well, that is, intersection $A$. In a similar way, the origin of the local cylindrical coordinate system (LCCS), denoted by the coordinate $\left(r_{3}, z_{1}\right)$, for the production well is located at the bottom of the production well, that is, $\left(L_{2}, 0, L_{1}\right)$ in the GCS.

In order to make the problem tractable, some assumptions are made:

(a) The fluid is single phase, incompressible, and Newtonian, and the rock is impermeable.

(b) The material properties of the fluid and the rock are constants, independent of temperature.

(c) When there are multiple layers around the wellbore, the heat transfer through the layers is characterized by one overall heat transfer coefficient.

(d) The heat diffusion around the wellbore can be regarded to be axis-symmetric.

Assumption (d) is the most important one based on which the present model is simplified. According to Jiji [50, page 242-246], for a semi-infinite domain with a homogenous initial temperature and one time-dependent surface heat flux imposed at the boundary at time $t>0$, the penetration depth of the thermal layer is in the order of $\left(6 \kappa_{r} t\right)^{1 / 2}$, where $\kappa_{r}=\lambda_{r} /\left(\rho_{r} c_{r}\right)$ is the thermal diffusivity with $\lambda_{r}, \rho_{r}$, and $c_{r}$ being the thermal conductivity, mass density, and specific heat capacity, respectively, of the media. Take shale, for example, when $\lambda_{r}=1.42 \mathrm{~W} /(\mathrm{m} \cdot \mathrm{K}), \rho_{r}=$ $2057 \mathrm{Kg} / \mathrm{m}^{3}$, and $\mathrm{c}_{r}=2151 \mathrm{~J} /(\mathrm{Kg} \cdot \mathrm{K})(\mathrm{pp} \mathrm{106},[8])$, the thermal diffusivity $\kappa_{r}=3.209 \times 10^{-7} \mathrm{~m}^{2} / \mathrm{s}$. This means that, after 60 days and 30 years, the thermal layer is about $3.16 \mathrm{~m}$ and $42.68 \mathrm{~m}$, respectively, illustrating the slow movement of the thermal front in rock. Because the reservoir size is large enough (say in the order of $1 \mathrm{~km}$ ), the interaction of heat transfer in the horizontal and vertical directions around the bottom of the vertical wells can be neglected.
Based on the above assumptions, the current model can be simplified greatly without causing large errors in predicting the temperature profiles.

2.2. Governing Equations. The governing equations can be written in the corresponding local cylindrical coordinate system (LCCS) for the vertical and horizontal parts of the well. Besides, temperature continuity is enforced at the intersection point at the heel of the horizontal well.

2.2.1. Heat Exchange along the Wellbore. As the heat flow is uniform along the well, the transient energy equations for the fluid flow are written as follows, according to their LCCSs [28]:

$$
\begin{aligned}
& \rho_{f} \mathcal{c}_{f} A_{1} v_{1} \frac{\partial T_{f 1}}{\partial z}+2 \pi r_{t 1} U_{1}\left(T_{f 1}-T_{b 1}\right) \\
& =-\rho_{f} \mathcal{c}_{f} A_{1} \frac{\partial T_{f 1}}{\partial t}, \quad \text { (injection), } \\
& \rho_{l} \mathcal{c}_{l} A_{3} v_{3} \frac{\partial T_{f 3}}{\partial z_{1}}+2 \pi r_{t 3} U_{3}\left(T_{b 3}-T_{f 3}\right)=\rho_{f} \mathcal{c}_{f} A_{3} \frac{\partial T_{f 3}}{\partial t},
\end{aligned}
$$

(production),

for the vertical wells, and

$$
\begin{gathered}
\rho_{f} c_{f} A_{2} v_{2} \frac{\partial T_{f 2}}{\partial x}+2 \pi r_{t 2} U_{2}\left(T_{f 2}-T_{b 2}\right) \\
=-\rho_{f} \mathcal{c}_{f} A_{2} \frac{\partial T_{f 2}}{\partial t}
\end{gathered}
$$

for the horizontal well, where $\rho_{f}$ and $c_{f}$ are the mass density and specific heat capacity, respectively, of the fluid and $r_{t \ell}, A_{\ell}$, $U_{\ell}, v_{\ell}, T_{f \ell}$, and $T_{b \ell}(\ell=1$ for injection, $\ell=2$ for horizontal, and $\ell=3$ for production) denote the radius of fluid flow 
channel, the areas of the wellbore cross section, overall heat transfer coefficients (OHTCs), fluid velocity in the wellbore, fluid temperature, and the temperature at the wellbore wall, respectively. The value of the radius of fluid flow channel will be determined based on the condition as follows. If fluid flows in a pipe, it is equal to the pipe radius; if the fluid contacts directly with the rock formation, it is equal to the wellbore radius; that is, $r_{t \ell}=r_{h \ell}$.

The OHTCs $U_{\ell}$ can be calculated based on Willhite's equation [51] which considers a multilayered wellbore structure

$$
\begin{aligned}
\frac{1}{U_{\ell}}= & \frac{r_{t o}}{r_{t \ell} h_{\ell}}+\frac{r_{t o} \ln \left(r_{t o} / r_{t \ell}\right)}{k_{\text {tub. }}}+\frac{r_{t o} \ln \left(r_{\text {ins. }} / r_{t o}\right)}{k_{\text {ins }}} \\
& +\frac{r_{t o}}{r_{\text {ins. }}\left(h_{c}^{\prime}+h_{r}^{\prime}\right)}+\frac{r_{t o} \ln \left(r_{c o} / r_{c i}\right)}{k_{\text {cas. }}} \\
& +\frac{r_{t o} \ln \left(r_{h} / r_{c o}\right)}{k_{\text {cem. }}}
\end{aligned}
$$

where $\ell=1$ or 2 , for two well parts. The cross-section geometry can be found in Figure 1(b) and the subscripts provide the layers. $k$ denote the thermal conductivities for different layers. $h_{c}^{\prime}$ is the natural convection and conduction HTC through the annulus, and $h_{r}^{\prime}$ is the radiation HTC through the annulus; $h_{\ell}$ is the HTC between the fluid and tubing. If the effects of the annulus, casing, and cements are not taken into account, the first two terms on the right side of (3) are used to calculate $U_{\ell}$. If the fluid contacts directly with the rock formation, $r_{t o}=r_{t \ell}$ and $U_{\ell}=h_{\ell}$. From (3) we also know that the OHTC is mainly determined by the minimum value of the denominators of the terms on the right side. This indicates that if the thermal conductivity of some layer is very small, this layer will work as a thermal insulator.

When fluid flows in a tubing, the HTC between the fluid and tubing, that is, $h_{\ell}$, is obtained by using the relationship $\mathrm{Nu}_{\ell}=h_{\ell} D / k_{f}$, where $N_{u}$ denotes the Nusselt number, $k_{f}$ is the thermal conductivity of the fluid, and $D$ is the hydraulic diameter of the tubing. For fully developed laminar flow in a pipe with circular cross section, the Nusselt number $N_{u}=$ 3.66, while, for transitional and turbulent flows, the Nusselt number is obtained by using the well-known Gnielinski correlation [52]

$$
\begin{aligned}
\mathrm{Nu}=\frac{(\xi / 8)(\mathrm{Re}-1000) \operatorname{Pr}_{f}}{1+12.7 \sqrt{\xi / 8}\left(\operatorname{Pr}_{f}^{2 / 3}-1\right)}\left(\frac{\operatorname{Pr}_{f}}{\operatorname{Pr}_{r}}\right)^{0.11}, \\
\quad \xi=[0.79 \ln (\mathrm{Re})-1.64]^{-2},
\end{aligned}
$$

when $0.5<\operatorname{Pr}_{f}<2000$ and $3000<\operatorname{Re}<5 \times 10^{6}$. In the present model, the Reynolds and Prandtl numbers related to fluid flowing in the tubing or wellbore and the rock formation are expressed as

$$
\begin{aligned}
\operatorname{Re}_{\ell} & =\frac{\rho_{f} v_{\ell} 2 r_{t \ell}}{\mu}, \\
\operatorname{Pr}_{f} & =\frac{\mu c_{f}}{k_{f}}, \\
\operatorname{Pr}_{r \ell} & =\frac{\mu c_{r \ell}}{k_{r \ell}},
\end{aligned}
$$

where $\rho_{f}$ and $c_{f}$ denote the mass density and heat capacity, respectively, of the fluid and $k_{r \ell}$ and $c_{r \ell}$ denote the thermal conductivity and heat capacity, respectively, of the rock formation.

\subsubsection{Heat Conduction in the Rock Formation Surrounding} the Wellbore. As the radial heat conduction dominates the thermal diffusion process around the wellbore, the equations are written as follows in their corresponding LCCS:

$$
\frac{\partial T_{r \ell}}{\partial t}=\kappa_{r \ell} \frac{1}{r_{\ell}} \frac{\partial}{\partial r_{\ell}}\left[r_{\ell} \frac{\partial T_{r \ell}}{\partial r_{\ell}}\right], \quad(\ell=1,2,3),
$$

where $T_{r 1}, T_{r 2}$, and $T_{r 3}$ denote the temperature of the formation around the injection, horizontal, and production wells, respectively. The thermal diffusivities of the rock formation are denoted by $\kappa_{r \ell}=k_{r \ell} /\left(\rho_{r \ell} c_{r \ell}\right)$, with $\rho_{r \ell}$ being the mass density of the rock formation. It should be noted that the radial spatial variables for the injection, horizontal, and production wells are $r_{1}, r_{2}$, and $r_{3}$, respectively.

The heat transfer conditions between the rock and the whole well system are given as

$$
2 \pi r_{t \ell} U_{\ell}\left(T_{b \ell}-T_{f \ell}\right)=2 \pi r_{h \ell} \lambda_{r \ell} \frac{\partial T_{r \ell}}{\partial r_{\ell}}, \quad \text { at } r_{\ell}=r_{h \ell} .
$$

Based on the above equation, if the OHTC $U_{\ell}=0$, $\partial T_{r \ell} / \partial_{r \ell}=0$, indicating no heat flowing into or out of the rock formation. From the point of view of heat extraction, a thermal insulation layer along the production well can enhance the heat production by preventing the heat loss along the well during fluid flowing upwards.

2.3. Boundary and Initial Conditions. The injection rate $Q_{1}$ is prescribed and the injection temperature is

$$
T_{f 1}=T_{\text {in }}, \quad \text { at }(0,0,0) \text { in GCS. }
$$

The bottomhole temperature (BHT) of the vertical well is used as the input conditions for the horizontal well and the output temperature of the horizontal well is used as the input conditions for the production well, that is, at the intersections $A$ and $B$

$$
\begin{aligned}
& T_{f 1}=T_{f 2}, \quad \text { at }(0,0, H) \text { in GCS, } \\
& T_{f 2}=T_{f 3}, \quad \text { at }(L, 0, H) \text { in GCS. }
\end{aligned}
$$


The ground temperature at the surface is a constant

$$
T_{r 1}=B_{0}, \quad \text { on } z=0 \text {, }
$$

and the initial temperature of the whole system is a function of depth

$$
T_{0}=A_{0} z+B_{0} .
$$

The heat extraction rate or thermal power output by the fluid with output temperature $T_{\text {out }}$ is expressed as

$$
W=Q_{3} \rho_{w} c_{w} T_{\text {out }}-Q_{1} \rho_{w} c_{w} T_{\text {in }}
$$

where $Q_{1}=Q_{3}=Q_{\text {in }}$ and from which the total heat extracted is

$$
\Phi=\int_{0}^{t} W(t) d t=\int_{0}^{t} Q_{\text {in }} \rho_{w} c_{w}\left(T_{\text {out }}-T_{\text {in }}\right) d t .
$$

\section{Dimensionless Formulation}

The governing equations, boundary and initial conditions, are simplified with the following transformation:

$$
\begin{aligned}
Z & =\frac{z}{L_{z}}, \\
X & =\frac{x}{L_{x}}, \\
R_{\ell} & =\frac{r_{\ell}}{r_{h \ell}}, \\
\tau & =\frac{\kappa_{r 1} t}{r_{h 1}^{2}}, \\
\Theta_{f \ell} & =\frac{T_{f \ell}}{T^{*}}, \\
\Theta_{b \ell} & =\frac{T_{b \ell}}{T^{*}}, \\
\Theta_{f \ell} & =\frac{T_{f \ell}}{T^{*}}, \\
\varepsilon_{\ell} & =\frac{\kappa_{r \ell} r_{h 1}^{2}}{\kappa_{r 1} r_{h \ell}^{2}}, \\
\mathrm{Bi}_{\ell} & =\frac{r_{t \ell} U_{\ell}}{\lambda_{r \ell}},
\end{aligned}
$$

$$
\begin{aligned}
\chi_{\ell} & =\frac{L_{\ell} \kappa_{r \ell}}{r_{h}^{2} v_{\ell}}, \\
\alpha_{\ell} & =\frac{2 \pi L_{\ell} r_{t \ell} U_{\ell}}{\rho_{f} c_{f} Q_{\ell}}, \\
\gamma_{1} & =\frac{A_{0} H}{T^{*}}, \\
\Theta_{r 1}^{0} & =\Theta_{f 1}^{0}=\gamma_{1}(Z-1)+1, \\
T^{*} & =A_{0} H+B_{0}, \\
L_{z} & =L_{1}, \\
L_{x} & =L_{2},
\end{aligned}
$$

where $\Theta_{f \ell}, \Theta_{b \ell}$, and $\Theta_{r \ell}(\ell=1$ for injection, $\ell=2$ for horizontal, and $\ell=3$ for production) denote dimensionless temperature in the fluid, at the wall and in the formation, respectively.

By using the above variables, the simplified formulation for the three subproblems of the original model is listed as follows.

(a) Injection Well. The governing and heat balance equations for the injection well are

$$
\begin{array}{cc}
\frac{\partial \Theta_{r 1}}{\partial \tau}=\frac{1}{R_{1}} \frac{\partial}{\partial R_{1}}\left[R_{1} \frac{\partial \Theta_{r 1}}{\partial R_{1}}\right], & \\
\operatorname{Bi}_{1}\left(\Theta_{b 1}-\Theta_{f 1}\right)=\frac{\partial \Theta_{r 1}}{\partial R_{1}} & \text { at } R_{1}=1, \\
\chi_{1} \frac{\partial \Theta_{f 1}}{\partial \tau}+\frac{\partial \Theta_{f 1}}{\partial Z}=\alpha_{1}\left(\Theta_{b 1}-\Theta_{f 1}\right), &
\end{array}
$$

with the initial and boundary conditions

$$
\begin{aligned}
& \Theta_{r 1}=\Theta_{f 1}=\gamma_{1}(Z-1)+1, \quad \text { on } \tau=0, \\
& \Theta_{f 1}=\Theta_{\text {in }}, \quad \text { at }(1,0) \text { in LCCS. }
\end{aligned}
$$

(b) Horizontal Well. The governing and heat balance equations for the horizontal well are

$$
\begin{array}{cc}
\frac{\partial \Theta_{r 2}}{\partial \tau}=\frac{\varepsilon_{2}}{R_{2}} \frac{\partial}{\partial R_{2}}\left[R_{2} \frac{\partial \Theta_{r 2}}{\partial R_{2}}\right], & \\
\operatorname{Bi}_{2}\left(\Theta_{b 2}-\Theta_{f 2}\right)=\frac{\partial \Theta_{r 2}}{\partial R_{2}} & \text { at } R_{2}=1, \\
\chi_{2} \frac{\partial \Theta_{f 2}}{\partial \tau}+\frac{\partial \Theta_{f 2}}{\partial X}=\alpha_{2}\left(\Theta_{b 2}-\Theta_{f 2}\right), &
\end{array}
$$


with the initial and boundary conditions becoming

$$
\begin{gathered}
\Theta_{f 2}=\Theta_{f 1}, \quad \text { at }(1,0) \text { in LCCS, } \\
\Theta_{r 2}=\Theta_{f 2}=1, \quad \text { on } \tau=0 .
\end{gathered}
$$

(c) Production Well. The governing and heat balance equations for the production well are

$$
\begin{aligned}
& \frac{\partial \Theta_{r 3}}{\partial \tau}=\frac{\varepsilon_{3}}{R_{3}} \frac{\partial}{\partial R_{3}}\left[R_{3} \frac{\partial \Theta_{r 3}}{\partial R_{3}}\right], \\
& \mathrm{Bi}_{3}\left(\Theta_{b 3}-\Theta_{f 3}\right)=\frac{\partial \Theta_{r 3}}{\partial R_{3}} \\
& \text { at } R_{3}=1 \text {, } \\
& \chi_{3} \frac{\partial \Theta_{f 3}}{\partial \tau}+\frac{\partial \Theta_{f 3}}{\partial Z}=\alpha_{3}\left(\Theta_{b 3}-\Theta_{f 3}\right),
\end{aligned}
$$

with the initial and boundary conditions

$$
\begin{aligned}
& \Theta_{r 3}=\Theta_{f 3}=\gamma_{3} \bar{Z}+1, \quad \text { on } \tau=0, \\
& \Theta_{f 3}=\Theta_{f 2}, \quad \text { at }(0,0) \text { in LCCS, }
\end{aligned}
$$

where $\bar{Z}=1-Z$ denotes the distance of the point from the bottom of production well, $\gamma_{3}=-\gamma_{1}$. The subproblem for production well is similar to that for injection well as it can be regarded as a model with the origin of the CS at the bottom of production well and with a negative geothermal gradient $\gamma_{3}=-\gamma_{1}$.

\section{Solution Method}

By using the Laplace transformation, the analytical solutions for the three stages are obtained. In the following equations, the symbol $\wedge$ denotes the variables which are Laplace transformed and $s$ is a complex number as the Laplace symbol. For example, $\widehat{f}(s)$ denotes the Laplace transform of the function $f(t)$.

4.1. Injection Well. From the Laplace transform of the governing equation, that is, the first of (15), for the heat diffusion in the rock around the injection well, we obtain the rock temperature

$$
\begin{aligned}
\widehat{\Theta}_{r 1}= & F_{1}(Z, s) K_{0}\left(\sqrt{s} R_{1}\right)+F_{2}(Z, s) I_{0}\left(\sqrt{s} R_{1}\right) \\
& +\frac{\gamma_{1}(Z-1)+1}{s},
\end{aligned}
$$

where $\widehat{\Theta}_{r 1}$ is the Laplace transform of the dimensionless temperature $\Theta_{r 1} ; I_{n}$ and $K_{n}$ are the modified Bessel functions of the first and second kind of order $n$, respectively; and $F_{1}(s)$ and $F_{2}(s)$ are unknowns to be determined by the boundary conditions. As $\Theta_{r 1}$ is finite when $R_{1} \rightarrow+\infty$, it is easy to know that $F_{2}(Z)=0$. Therefore, the temperature at the wellbore wall is obtained

$$
\widehat{\Theta}_{b 1}=\left.\widehat{\Theta}_{r 1}\right|_{R_{1}=1}=F_{1}(Z, s) K_{0}(\sqrt{s})+\frac{\gamma(Z-1)+1}{s} .
$$

By substituting (21) and (22) into the second of (15) we have

$$
\begin{array}{r}
\widehat{\Theta}_{f 1}=F_{1}(Z, s) \Delta+\frac{\gamma(Z-1)+1}{s}, \\
\Delta=\frac{\sqrt{s} K_{1}(\sqrt{s})}{\mathrm{Bi}_{1}}+K_{0}(\sqrt{s}),
\end{array}
$$

which, after being used in the third of (15), produces an ordinary differential equation with respect to the unknown $F_{1}(Z, s)$; that is,

$$
\frac{\mathrm{d} F_{1}}{\mathrm{~d} z}+\frac{\beta_{1}}{\Delta_{1}} F_{1}+\frac{\gamma_{1}}{s \Delta_{1}}=0
$$

$$
\text { where } \beta_{1}=\chi_{1} s \Delta_{1}+\alpha_{1}\left(\Delta_{1}-K_{0}(\sqrt{s})\right) \text {. }
$$

The solution of the above equation is found to be

$$
F_{1}(Z, s)=-\frac{\gamma_{1}}{s \beta}+e^{-\beta Z / \Delta} C_{1}(s)
$$

where the unknown function $C_{1}(\mathrm{~s})$ can be determined by using (23), (25), and the injection boundary condition (16)

$$
C_{1}=\frac{\widehat{\Theta}_{\text {in }} s \beta+\beta \gamma_{1}-\beta+\Delta \gamma_{1}}{s \beta \Delta}=\frac{\widehat{\Theta}_{i n} s+\gamma_{1}-1}{s \Delta}+\frac{\gamma_{1}}{s \beta} .
$$

Therefore, the solutions for the temperatures of the rock, $\widehat{\Theta}_{r 1}$, and fluid, $\widehat{\Theta}_{f 1}$, are obtained and rewritten as

$$
\begin{aligned}
\widehat{\Theta}_{r 1}= & {\left[\frac{\widehat{\Theta}_{\mathrm{in}} s+\gamma_{1}-1}{s} A_{1}+\frac{\gamma_{1}}{s} A_{2}\right] e^{-Z / A_{3}}-\frac{\gamma_{1}}{s} A_{2} } \\
& +\frac{\gamma_{1}(Z-1)+1}{s}, \\
\widehat{\Theta}_{f 1}= & {\left[\frac{\widehat{\Theta}_{\mathrm{in}} s+\gamma_{1}-1}{s}+\frac{\gamma_{1}}{s} A_{3}\right] e^{-Z / A_{3}}-\frac{\gamma_{1}}{s} A_{3} } \\
& +\frac{\gamma_{1}(Z-1)+1}{s},
\end{aligned}
$$

where the functions $A_{1}, A_{2}$, and $A_{3}$ are defined as

$$
\begin{aligned}
& A_{1}=\frac{\mathrm{Bi}_{1} K_{0}\left(\sqrt{s} R_{1}\right) / K_{1}(\sqrt{s})}{\sqrt{s}+\mathrm{Bi}_{1} K_{0}(\sqrt{s}) / K_{1}(\sqrt{s})} \\
& A_{2}=\frac{\mathrm{Bi}_{1} K_{0}\left(\sqrt{s} R_{1}\right) / K_{1}(\sqrt{s})}{\chi_{1} s\left[\sqrt{s}+\mathrm{Bi}_{1} K_{0}(\sqrt{s}) / K_{1}(\sqrt{s})\right]+\alpha_{1} \sqrt{s}}, \\
& A_{3}=\frac{\sqrt{s}+\mathrm{Bi}_{1} K_{0}(\sqrt{s}) / K_{1}(\sqrt{s})}{\chi_{1} s\left[\sqrt{s}+\mathrm{Bi}_{1} K_{0}(\sqrt{s}) / K_{1}(\sqrt{s})\right]+\alpha_{1} \sqrt{s}},
\end{aligned}
$$

where $\widehat{\Theta}_{\text {in }}$ is the Laplace transform of the injection temperature. 
The Laplace transformation of the bottomhole temperature $(\mathrm{BHT})$ of the injection well is

$$
\begin{aligned}
\mathrm{BHT}_{1}= & G(s) \\
= & {\left[\frac{\widehat{\Theta}_{\mathrm{in}} s+\gamma_{1}-1}{s}+\frac{\gamma_{1}}{s} A_{3}\right] e^{-1 / A_{3}}-\frac{\gamma_{1}}{s} A_{3} } \\
& +\frac{1}{s},
\end{aligned}
$$

which will be used as the input condition for the horizontal well.

4.2. Horizontal Well. Initially, the temperature along horizontal well is identical due to the same depth. Based on the above calculations, the thermal front only penetrates less than 50 meters into the rock within 30 years. In the region between the upper and lower thermal front, the largest temperature is less than $4^{\circ} \mathrm{C}$. Therefore, it is reasonable to assume a constant temperature in the rock formation around the horizontal well.

In a similar way, the solutions for the horizontal well are obtained

$$
\begin{aligned}
& \widehat{\Theta}_{r 2}=\frac{s G(s)-1}{s} e^{-X / B_{3}} B_{1}+\frac{1}{s}, \\
& \widehat{\Theta}_{f 2}=\frac{s G(s)-1}{s} e^{-X / B_{3}}+\frac{1}{s},
\end{aligned}
$$

where the functions $B_{1}$ and $B_{3}$ are defined as

$$
\begin{aligned}
& B_{1}=\frac{\mathrm{Bi}_{2} K_{0}\left(\sqrt{s / \varepsilon_{2}} R_{2}\right) / K_{1}\left(\sqrt{s / \varepsilon_{2}}\right)}{\mathrm{Bi}_{2} K_{0}\left(\sqrt{s / \varepsilon_{2}}\right) / K_{1}\left(\sqrt{s / \varepsilon_{2}}\right)+\sqrt{s / \varepsilon_{2}}}, \\
& B_{3} \\
& =\frac{\sqrt{s / \varepsilon_{2}}+\mathrm{Bi}_{2} K_{0}\left(\sqrt{s / \varepsilon_{2}}\right) / K_{1}\left(\sqrt{s / \varepsilon_{2}}\right)}{\chi_{2} s\left[\sqrt{s / \varepsilon_{2}}+\mathrm{Bi}_{2} K_{0}\left(\sqrt{s / \varepsilon_{2}}\right) / K_{1}\left(\sqrt{s / \varepsilon_{2}}\right)\right]+\alpha_{2} \sqrt{s / \varepsilon_{2}}} .
\end{aligned}
$$

The Laplace transformation of the temperature at the end of the horizontal well, also BHT of the production well, is obtained by using $X=1$; that is,

$$
\mathrm{BHT}_{2}=H(s)=\frac{s G(s)-1}{s} e^{-1 / B_{3}}+\frac{1}{s},
$$

which will be used as the input condition for the production well.

4.3. Production Well. The temperatures for the fluid in the production well and neighboring rock formation can be obtained in the same way as those for injection and horizontal well and the calculation details are omitted here

$$
\begin{aligned}
\widehat{\Theta}_{r 3}= & {\left[\frac{H(s) s-1}{s} C_{1}+\frac{\gamma_{3}}{s} C_{2}\right] e^{-\bar{Z} / C_{3}}-\frac{\gamma_{3}}{s} C_{2} } \\
& +\frac{\gamma_{3} \bar{Z}+1}{s}, \\
\widehat{\Theta}_{f 3}= & {\left[\frac{H(s) s-1}{s}+\frac{\gamma_{3}}{s} C_{3}\right] e^{-\bar{Z} / C_{3}}-\frac{\gamma_{3}}{s} C_{3} } \\
& +\frac{\gamma_{3} \bar{Z}+1}{s},
\end{aligned}
$$

where the functions $C_{1}, C_{2}$, and $C_{3}$ are defined as

$$
\begin{aligned}
& C_{1}=\frac{\mathrm{Bi}_{3} K_{0}\left(\sqrt{s / \varepsilon_{3}} R_{1}\right) / K_{1}\left(\sqrt{s / \varepsilon_{3}}\right)}{\mathrm{Bi}_{3} K_{0}\left(\sqrt{s / \varepsilon_{3}}\right) / K_{1}\left(\sqrt{s / \varepsilon_{3}}\right)+\sqrt{s / \varepsilon_{3}}}, \\
& C_{2} \\
& =\frac{\mathrm{Bi}_{3} K_{0}\left(\sqrt{s / \varepsilon_{3}} R_{1}\right) / K_{1}\left(\sqrt{s / \varepsilon_{3}}\right)}{\chi_{3} s\left[\mathrm{Bi}_{3} K_{0}\left(\sqrt{s / \varepsilon_{3}}\right) / K_{1}\left(\sqrt{s / \varepsilon_{3}}\right)+\sqrt{s / \varepsilon_{3}}\right]+\alpha_{3} \sqrt{s / \varepsilon_{3}}}, \\
& =\frac{\sqrt{s / \varepsilon_{3}}+\mathrm{Bi}_{3} K_{0}\left(\sqrt{s / \varepsilon_{3}}\right) / K_{1}\left(\sqrt{s / \varepsilon_{3}}\right)}{\chi_{3} s\left[\sqrt{s / \varepsilon_{3}}+\mathrm{Bi}_{3} K_{0}\left(\sqrt{s / \varepsilon_{3}}\right) / K_{1}\left(\sqrt{s / \varepsilon_{3}}\right)\right]+\alpha_{3} \sqrt{s / \varepsilon_{3}}} .
\end{aligned}
$$

The Laplace transformation of the temperature at the end of the horizontal well, also BHT of the production well, is obtained by using $X=1$; that is,

$$
\mathrm{BHT}_{2}=H(s)=\frac{s G(s)-1}{s} e^{-1 / B_{3}}+\frac{1}{s},
$$

which will be used as the input condition for the production well.

\section{Validation and Numerical Results}

5.1. Method Validation. In the present model, in order to obtain analytical solutions for temperature prediction in a closed-loop geothermal reservoir, the wellbore for fluid flow and heat transfer is divided into three parts with the output of one well part as the input conditions of the next well part. In order to show that these assumptions are reasonable and to show the error resulting from decoupling of the whole process, the results from the present model are compared with those from numerical simulator TOUGH 2. An automatic Laplace inversion technique developed by D'Amore et al. [53] based on Fourier series is used in the present model to obtain the values in the time space.

Figure 2 shows spatial discretization of the rock formation for the numerical calculation by using TOUGH2. As the temperature of the fluid in the radial direction in the pipe is assumed to be the same, it is denoted by blue node. The node for the rock is located in the middle of the each element. Figure 3 compares the temperature variations at points $A$, 


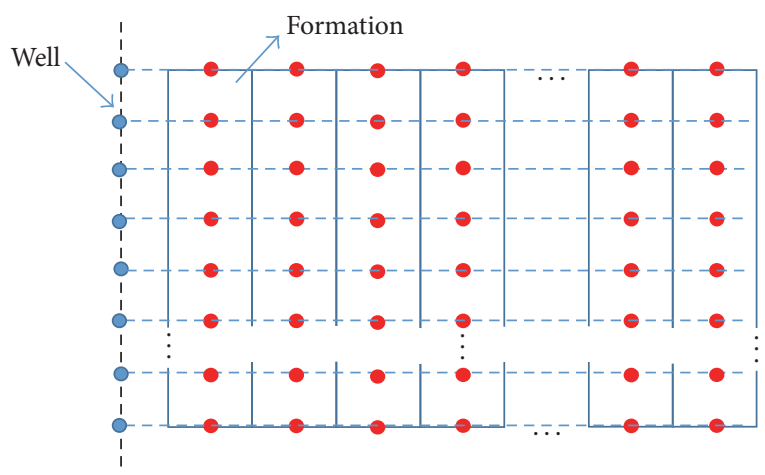

FIGURE 2: Grid for numerical calculation by using TOUGH2. The blue node is for the fluid and red node for the rock formation.

$B$, and $C$, which corresponds to the output points of the injection, horizontal, and production well parts, respectively, between TOUGH2 [37] and the present model. The solid curves denote results from TOUGH2 and the dashed ones are results from the present model. Figures 3(a) and 3(b) are for temperatures at short (20 days) and long (2.74 years) times of circulation, respectively, for the case $Q=0.05 \mathrm{~m}^{3} / \mathrm{s}$, while Figures 3(c) and 3(d) are for small $Q=0.01 \mathrm{~m}^{3} / \mathrm{s}$ and large $Q=0.20 \mathrm{~m}^{3} / \mathrm{s}$, respectively. Other parameters used here are $L_{1}=2000 \mathrm{~m}, L_{2}=3000 \mathrm{~m}, B_{0}=20^{\circ} \mathrm{C}$, and $T_{\text {in }}=30^{\circ} \mathrm{C}$.

It can be seen that the temperature results at points $A, B$, and $C$ predicted from both methods do not match at short time period, say 10 days, as shown in Figure 3(a) for the case when $Q=0.05 \mathrm{~m}^{3} / \mathrm{s}$. The temperature difference is mainly caused by the neglect of thermal interaction at the heel of the injection and production wells (i.e., around points $A$ and $B$ ) in the present model. However, for large time of circulation, the difference in the temperature results from both methods is very small, generally less than $4^{\circ} \mathrm{C}$, as shown in Figure 3(b). The temperature differences after 365 days and 1000 days between the present model and TOUGH 2 are $-3.87^{\circ} \mathrm{C}$ and $-3.65^{\circ} \mathrm{C}$, respectively. In order to further show the accuracy of the present model, the temperatures at these three points in another two cases, that is, $Q=0.01 \mathrm{~m}^{3} / \mathrm{s}$ and $Q=0.20 \mathrm{~m}^{3} / \mathrm{s}$, are also compared with those obtained from TOUGH2 and show good agreement. This means that the present model can be used to predict approximately the output temperature of the closed-loop system without causing large errors.

5.2. Numerical Results. In this section, the case with fluid fully contacted (without any tubing, casing, and cement) with the wellbore is first investigated. Under this condition, the radius of the tubing for fluid flow, $r_{t i}$, is equal to the wellbore radius, $r_{h i}$. By doing so, two objectives are achieved. First, the important factors affecting the fluid and heat flow behaviour are identified; second, the critical location determining whether the heat is flowing into or out of the rock formation is identified for thermal isolation design, especially for production well. Water is chosen for the fluid; sandstone and shale are chosen for the rock around the vertical and horizontal wells, respectively, for the following
TABLE 1: Physical parameters for the present calculation (the parameter values for thermal properties of shale are from Eppelbaum et al. [8] and the value of geothermal gradient is from Quick et al. [9]).

\begin{tabular}{lc}
\hline Parameter & Value \\
\hline Wellbore radius, $r_{h}(\mathrm{~m})$ & 0.1 \\
Length of vertical well, $H(\mathrm{~m})$ & 2000 \\
Length of horizontal well $(\mathrm{m})$ & 3000 \\
Geothermal gradient, $A_{0}(\mathrm{~K} / \mathrm{m})$ & 0.047 \\
Surface temperature, $B_{0}\left({ }^{\circ} \mathrm{C}\right)$ & 20 \\
Fluid density $\left(\mathrm{Kg} /\left(\mathrm{m}^{3}\right)\right)$ & 900 \\
Injection rate, $Q\left(\mathrm{~m}^{3} / \mathrm{s}\right)$ & 0.05 \\
Injection temperature $\left({ }^{\circ} \mathrm{C}\right)$ & 30.0 \\
Fluid specific heat $(\mathrm{J} /(\mathrm{Kg} \cdot \mathrm{K}))$ & 4200 \\
Fluid thermal conductivity $(\mathrm{W} /(\mathrm{m} \cdot \mathrm{K}))$ & 0.68 \\
Fluid viscosity $(\mathrm{Pa} \cdot \mathrm{s})$ & 0.0004 \\
Shale thermal conduct $(\mathrm{W} /(\mathrm{m} \cdot \mathrm{K}))$ & 1.42 \\
Shale specific heat $(\mathrm{J} /(\mathrm{Kg} \cdot \mathrm{K}))$ & 2151 \\
Shale density $\left(\mathrm{Kg} /\left(\mathrm{m}^{3}\right)\right)$ & 2057 \\
\hline
\end{tabular}

calculations. The parameters used for the examples are listed in Table 1 unless otherwise specified.

5.2.1. Temperature along the Vertical Wells. Figure 4 displays the dimensionless temperature changes, which are defined by physical temperature changes with respect to the initial state divided by $\left(A_{0} H+B_{0}\right)$, along the injection and production wells, respectively. The red curves refer to the initial state. For the injection well, we can see from Figure 4(a) that (1) before the cold fluid reaches the bottom of the wellbore, the temperature change of the fluid on the upper part of the wellbore decreases linearly with depth, while that on the lower part of the wellbore is almost a constant; (2) the temperature along the injection well decreases very quickly, with a temperature of $46.3^{\circ} \mathrm{C}$ at the bottom after 3 hours of circulation; and (3) as the injection temperature is lower than the initial ground temperature for most of the well length, most of the fluid flowing downwards absorbs heat from the surrounding rock except a small portion of fluid on the upper part of the wellbore. 


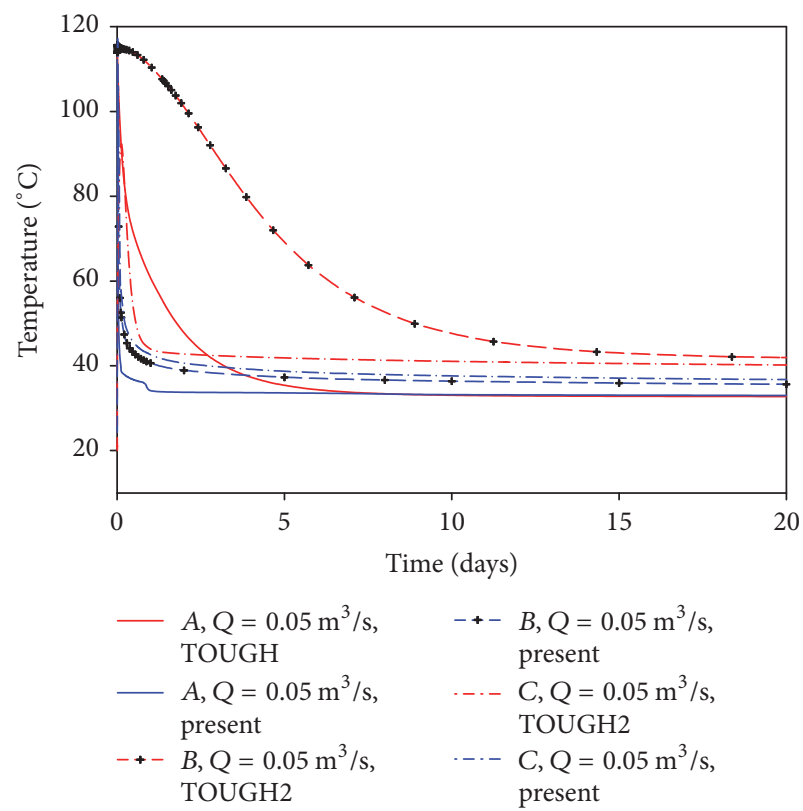

(a)

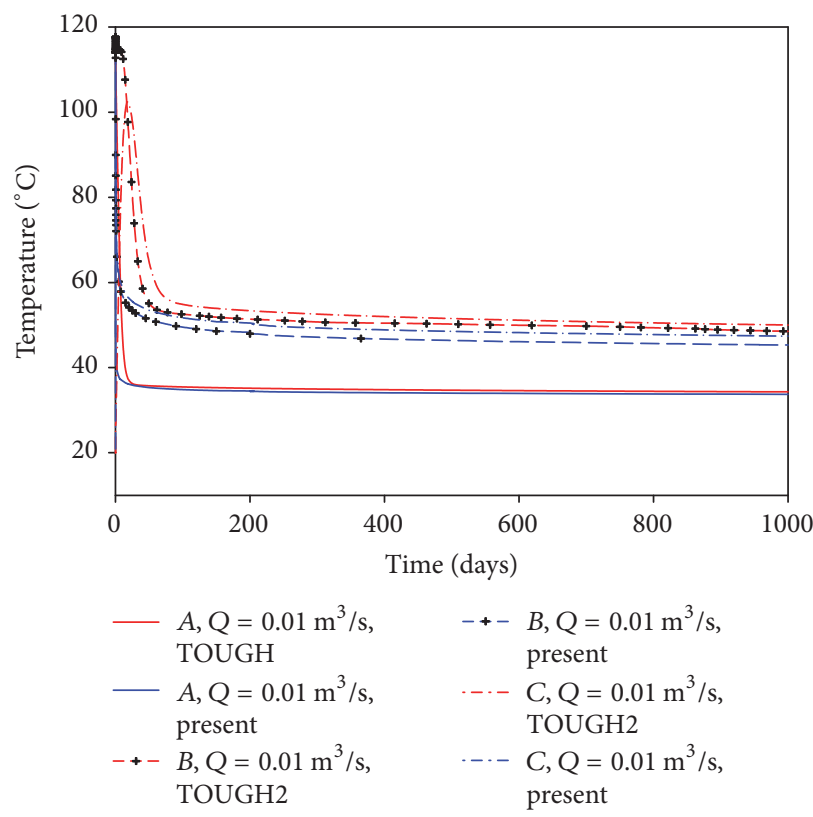

(c)

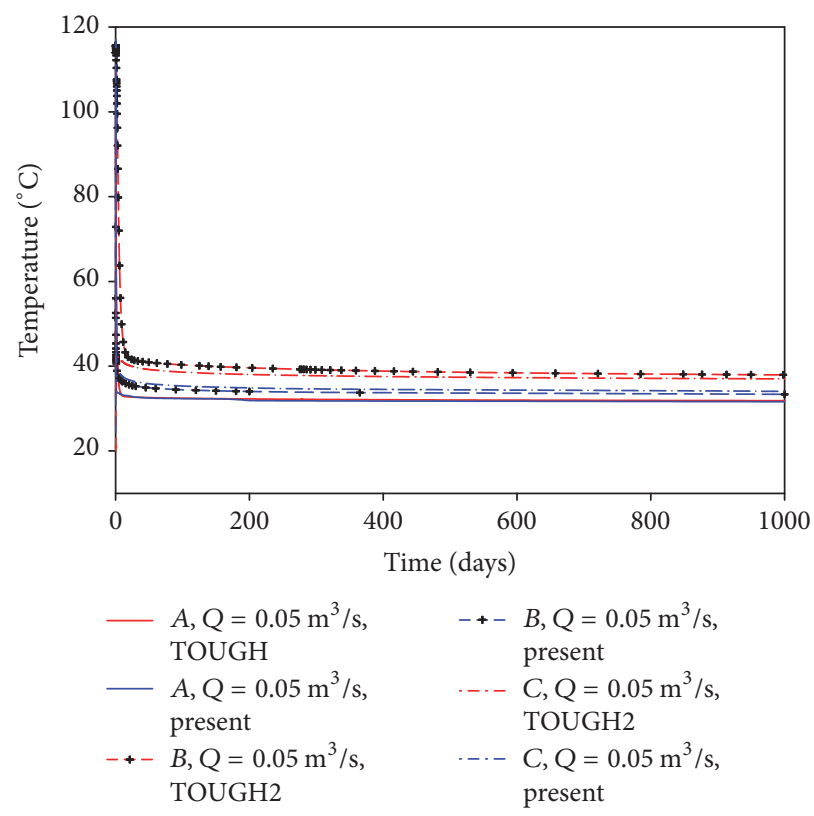

(b)

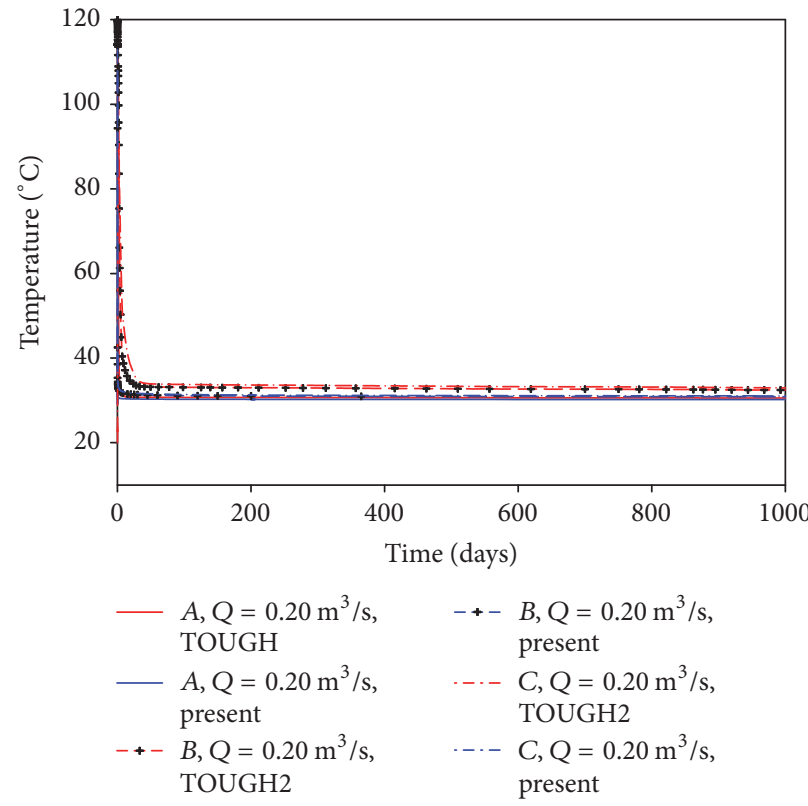

(d)

FIgure 3: Comparison of the temperatures at points $A, B$, and C. (a) For small time and (b) for large time when $Q=0.05 \mathrm{~m}^{3} / \mathrm{s}$; (c) for small $Q=0.01 \mathrm{~m}^{3} / \mathrm{s}$ and $(\mathrm{d})$ for large $Q=0.2 \mathrm{~m}^{3} / \mathrm{s}$.

Before the cold fluid reaches the production well, the temperature along the whole production well increases because of hot fluid flowing upwards, as shown by solid and dashed curves in Figure 4(b). The production temperature increases from $57^{\circ} \mathrm{C}$ to $152^{\circ} \mathrm{C}$ when the time varies from 10 mins to 1.0 hours and then decreases to $126^{\circ} \mathrm{C}$ after 3 hours. The small difference in temperature change between times $t=10$ days and $t=30$ years means that the heat transfer in the fluid approaches pseudo-steady state after 10 days. Moreover, the critical position which indicates if the fluid absorbs heat from or releases heat to the rock formation is around $Z_{c}=0.2$ or $z_{c}=700 \mathrm{~m}$.

5.2.2. Effect of Flow Rates on Output Performance. Figure 5 presents the output temperature for different injection rates ranging from $Q=0.01 \mathrm{~m}^{3} / \mathrm{s}$ to $0.14 \mathrm{~m}^{3} / \mathrm{s}$. It can be seen that the injection rate plays a major influence on the output temperature. First, for each injection rate, the output temperature increases quickly to a maximum value, as shown 


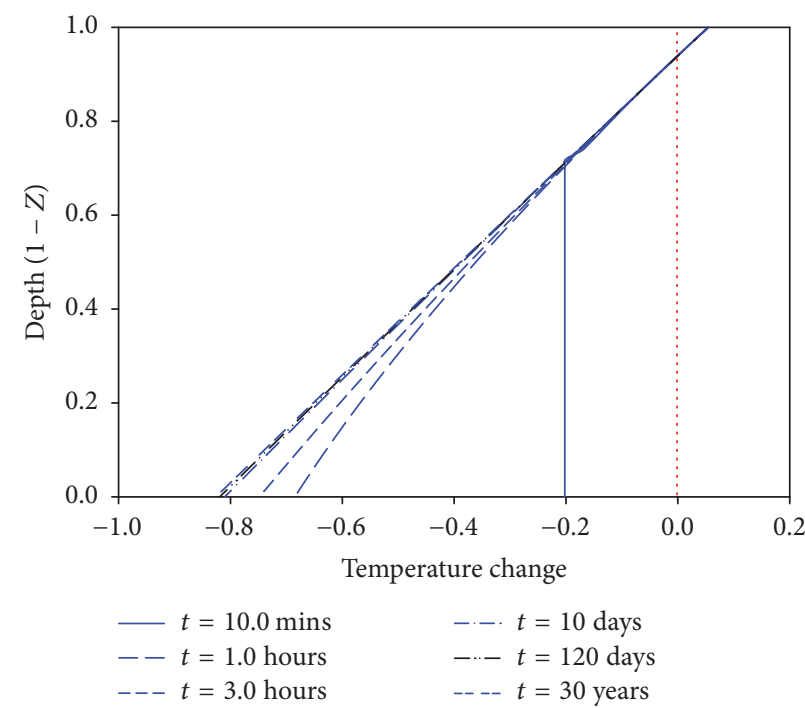

(a)

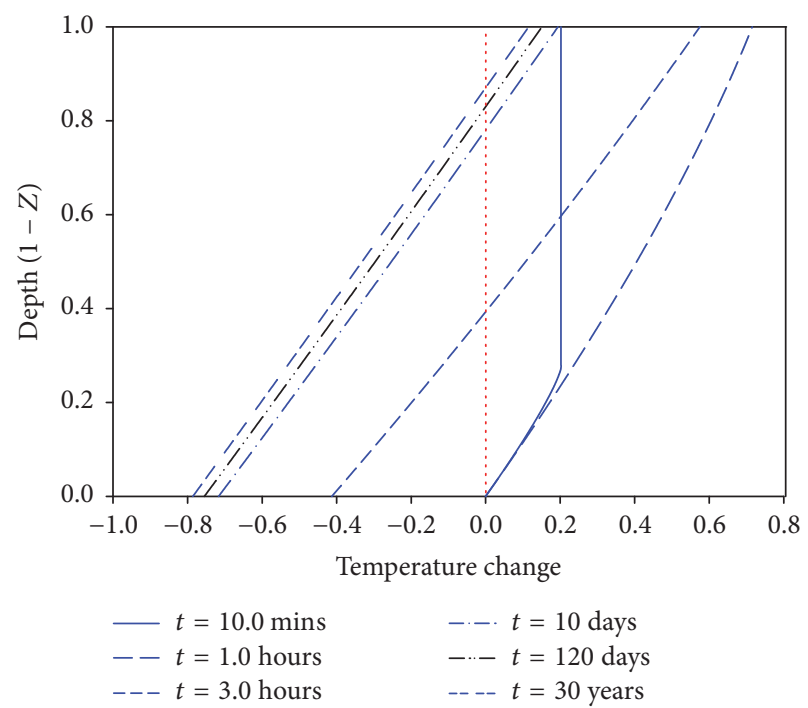

(b)

FIGURE 4: Temperature change profiles along the (a) injection and (b) production wells when $Q=0.05 \mathrm{~m}^{3} / \mathrm{s}, L_{1}=3500 \mathrm{~m}$, and $L_{2}=6000 \mathrm{~m}$.

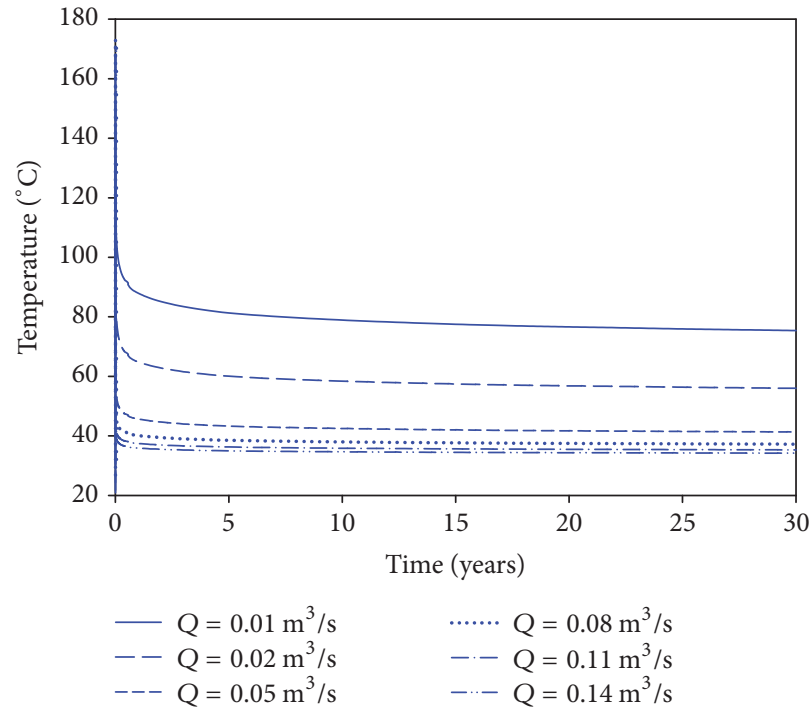

(a)

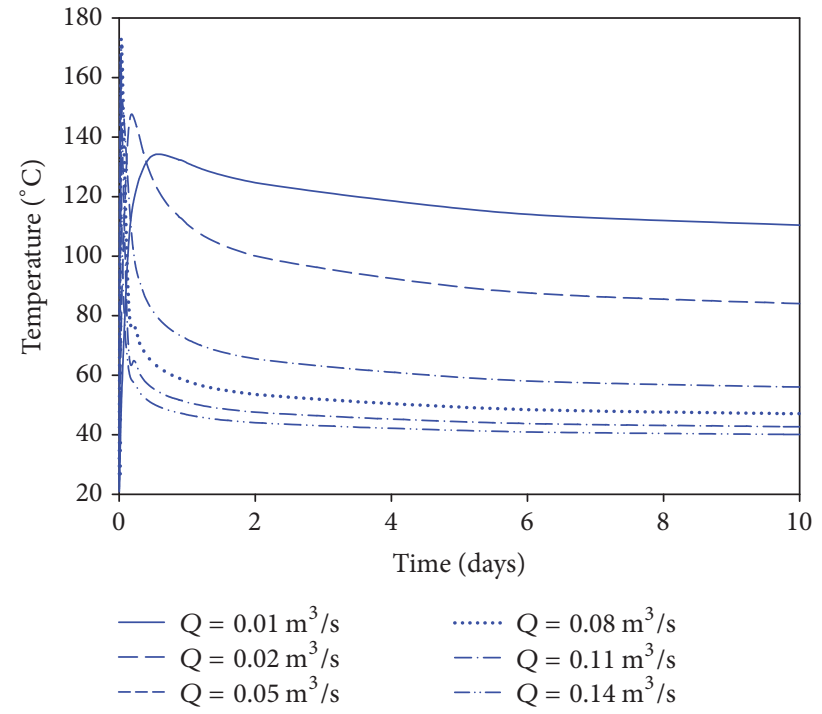

(b)

FIGURE 5: Variation with time of output temperature of the production well under different injection rates when $L_{1}=3500 \mathrm{~m}$ and $L_{2}=6000 \mathrm{~m}$ : (a) for general view and (b) for local view.

in Figure 5(b), and then decreases steadily to a constant value, as shown in Figure 5(a). Second, with increasing the injection rate, the production temperature is decreased. This is due to shortened time as a result of larger fluid speed for heat exchange between fluid and the surrounding rock. In addition, the temperature difference after 30 years between the cases $Q=0.01 \mathrm{~m}^{3} / \mathrm{s}$ and $Q=0.14 \mathrm{~m}^{3} / \mathrm{s}$ is around $40^{\circ} \mathrm{C}$. However, when the injection rate is increased to some value $\left(0.05 \mathrm{~m}^{3} / \mathrm{s}\right.$ for the present case), there is no large difference in the final production temperature, as shown in Figure 5(a).
The thermal power and total heat extracted for the above cases are plotted in Figure 6. According to the definition of thermal power in (12), thermal power is linearly proportional to the injection rate and temperature. However, as lower production temperature is obtained when the injection rate is increased, the curves for thermal power shown in Figure 6(b) do not exhibit similar trends to the production temperature in Figure 5(b). It has to be mentioned that the long-time thermal power ranges from 1.71 MWs to 2.21 MWs when $Q$ is changed from $0.01 \mathrm{~m}^{3} / \mathrm{s}$ to $0.14 \mathrm{~m}^{3} / \mathrm{s}$. 


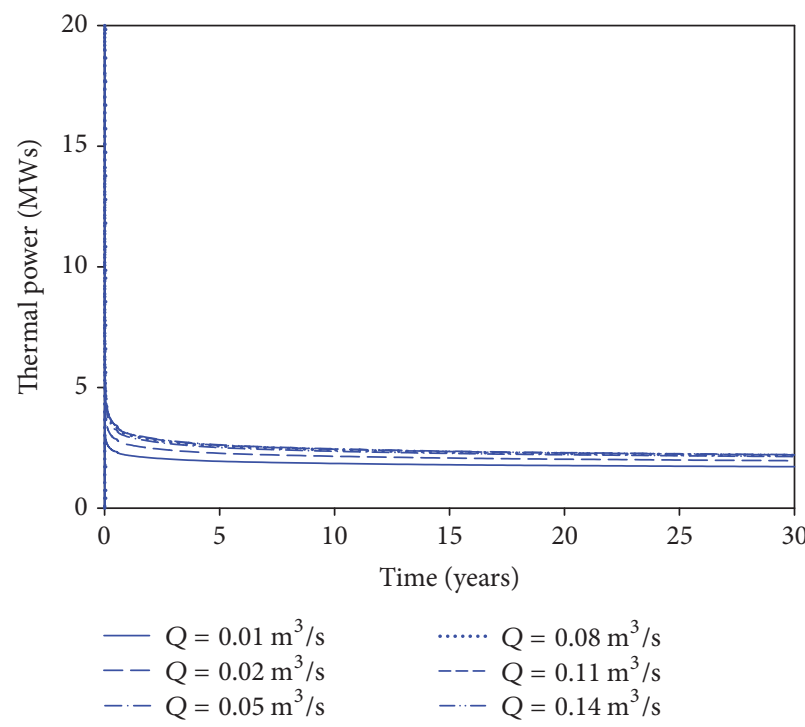

(a)

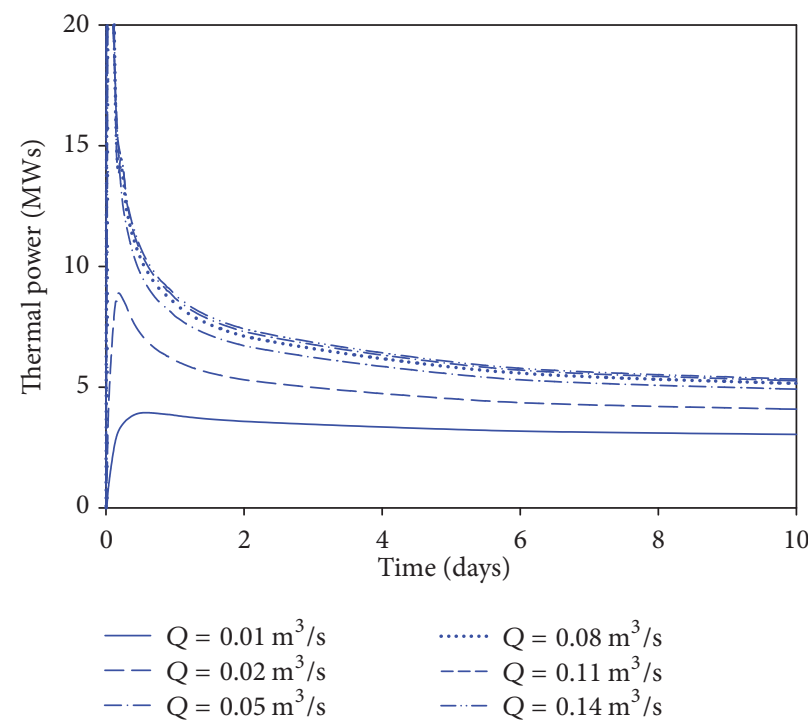

(b)

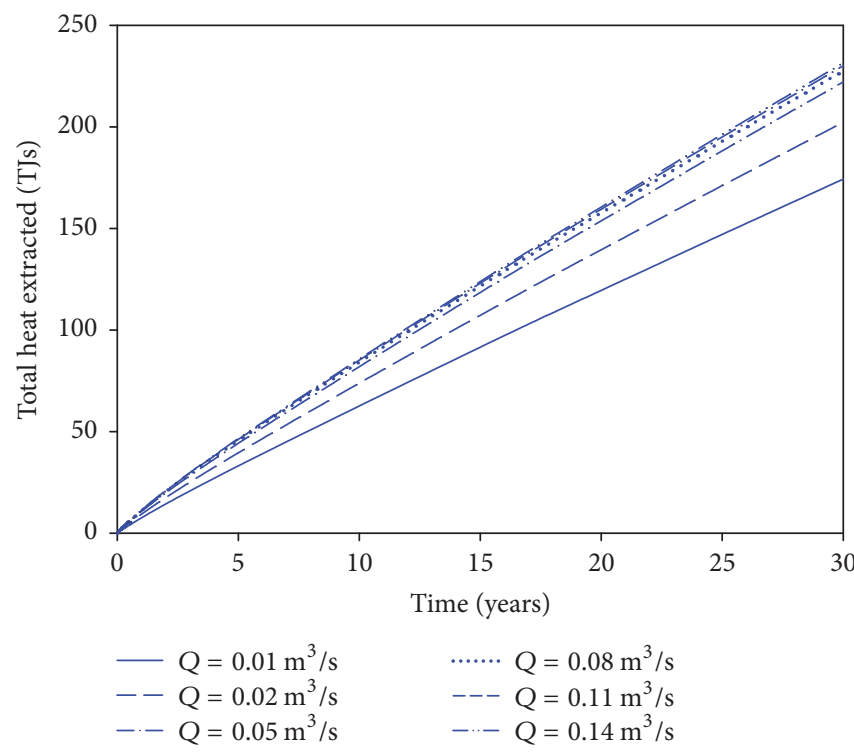

(c)

Figure 6: Thermal power and total heat extracted for different injection rates: thermal power (a) for large time and (b) for short time and (c) total heat extracted.

Figure 6(c) displays the total heat extracted from the reservoir up to 30 years under different injection rates. The total heat extracted is expected to increase when the injection rate is increased. However, the total heat extracted after 30 years when $Q=0.14 \mathrm{~m}^{3} / \mathrm{s}$ is only $32.75 \%$ larger than that when $Q=0.01 \mathrm{~m}^{3} / \mathrm{s}$. This means that the cost related to higher pressure required for larger flow rates has to be balanced with the total energy extracted.

\subsubsection{Effect of Injection Temperatures on Output Performance.} The effect of injection temperatures on output performance is displayed in Figures 7 and 8. As for output temperature, it increases evenly with increasing the injection temperature, as shown in Figure 7(a), and the maximum value of output temperature is not sensitive to the injection temperature, as shown in Figure 7(b).

Figure 8 presents the thermal power and total heat extracted up to 30 years. As the thermal power is linearly proportional to the temperature and the injection rate is kept constant, the thermal power exhibits a similar trend to the output temperature, as shown in Figures 8 and 7. In addition, it is interesting to find that although higher output temperature is obtained under larger injection temperature, the total heat extracted from the reservoir is reduced, as shown in Figure 8(c).

5.2.4. Effect of Fluid Viscosity on Output Performance. Figures 9 and 10 display the final output performance for different 


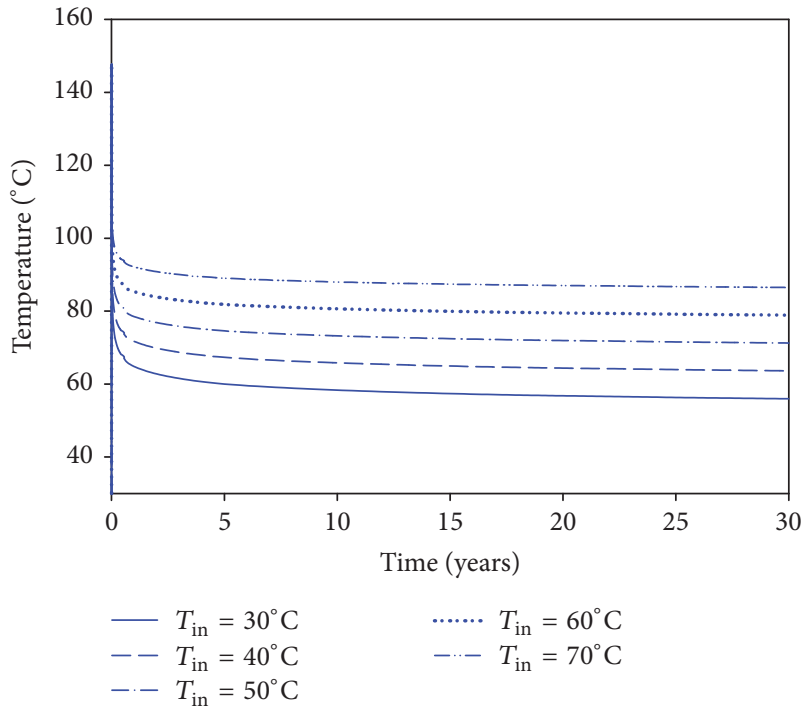

(a)

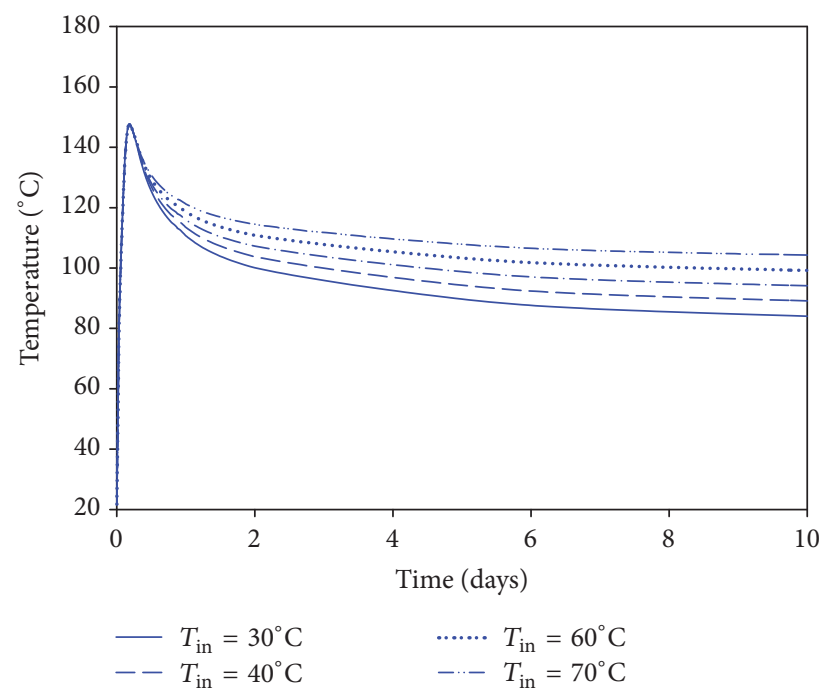

(b)

FiguRE 7: Variation with time of output temperature of the production well under different injection temperatures: (a) for large time period and (b) for short time period.

fluid viscosities. The water viscosity ranges from about 2.8 $\times 10^{-4} \mathrm{~Pa} \cdot \mathrm{s}$ to $1.3 \times 10^{-3} \mathrm{~Pa} \cdot \mathrm{s}$ when the temperature changes from $100^{\circ} \mathrm{C}$ to $10^{\circ} \mathrm{C}$, which can be found in the website link (https://en.wikipedia.org/wiki/viscosity). Here $\mu=10^{-4}, 5 \times$ $10^{-4}, 2.5 \times 10^{-3}$, and $1.2 \times 10^{-2} \mathrm{~Pa} \cdot \mathrm{s}$ are chosen to show the effect of the viscosity on the output temperature. From Figure 9 the output temperature follows almost the same curve under these four cases and the decreasing trend for rapid temperature drop in less than $5 \mathrm{hrs}$ is insensitive to the fluid viscosity.

5.2.5. Effect of Geothermal Gradient on the Output Performance. The output temperatures under different gradient geothermal gradients, $A_{0}$, are displayed in Figure 11 when other parameters are kept the same. It can be found that (1) as the depth of the vertical well is the same, larger geothermal gradient produces larger maximum output temperature (MOT), which is increased by around $42.2^{\circ} \mathrm{C}$ if $A_{0}$ has an increase of $1.5^{\circ} \mathrm{C}$. For example, the MOTs for the cases with $A_{0}=0.020,0.035,0.050,0.065,0.080$, and $0.095 \mathrm{~K} / \mathrm{m}$ are 76.2 , $118.4,160.5,202.7,244.9$, and $287.0^{\circ} \mathrm{C}$, respectively. However, the output temperature after a long time (say 30 years) is found to be increased by around $4^{\circ} \mathrm{C}$ when $A_{0}$ has an increase of $1.5^{\circ} \mathrm{C}$, as shown in Figure 11(b), where the output temperature is $34.2,38.2,42.1,46.0,49.9$, and $53.8^{\circ} \mathrm{C}$, respectively, for the above six cases. This means that, compared to the injection conditions, the geothermal gradient plays much less important role in the output performance.

5.2.6. Fully Insulated Case. Figure 12 compares the production temperatures under fully contacted and fully insulated conditions. The parameters used for the fully insulated case are the same as those in Figure 4 except that the overall heat transfer coefficient along the production well is set to zero.

It is found from Figure 12 that there is no large difference in production temperature between these two cases and the production temperature predicted from fully insulated case is a little smaller than that predicted from fully contacted case. From the curves for $t=10$ days and $t=30$ years in Figure 4(b) without any casing and cementing, it can be found that (1) the final output temperature decreases very quickly and approaches some pseudo-steady value which is dominated by the inject conditions and (2) the fluid along a larger part (around 80 percent) of wellbore length absorbs heat from the surrounding rock formation and the fluid along the rest of the wellbore releases heat into the formation. Compared with this openhole case, if an insulated layer is put along the whole wellbore, the final output temperature will become smaller although the heat loss into the formation, which occurs along a small part of wellbore length in the openhole case, is prevented in the insulated case, as confirmed in Figure 12.

\section{Conclusion}

This paper deals with the heat extraction from a closedloop geothermal system. Through reasonable assumptions and the temperature continuity conditions at the intersection, the whole well is divided into three portions, two vertical wellbores and one horizontal wellbore, which can be solved independently based on the input conditions. Conclusions 


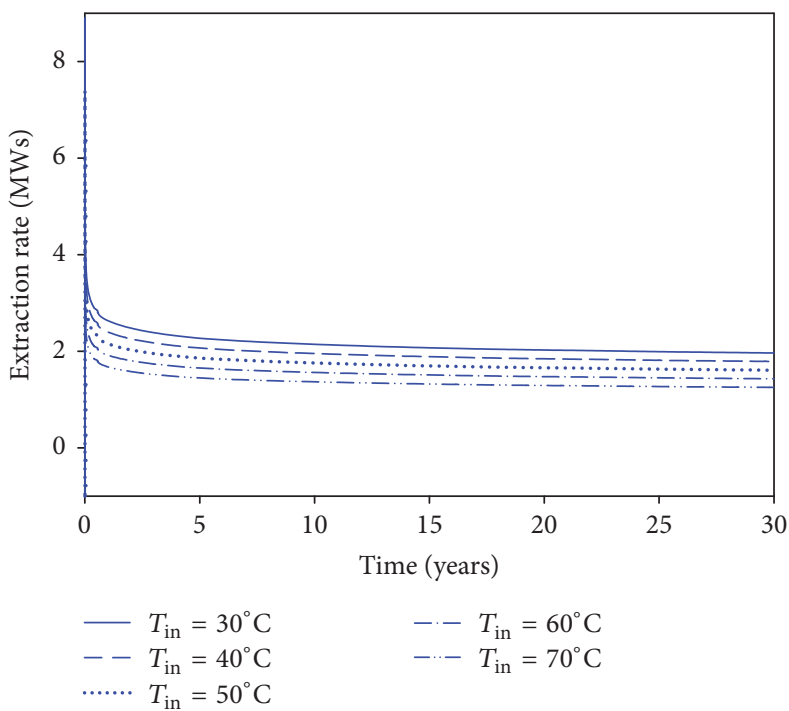

(a)

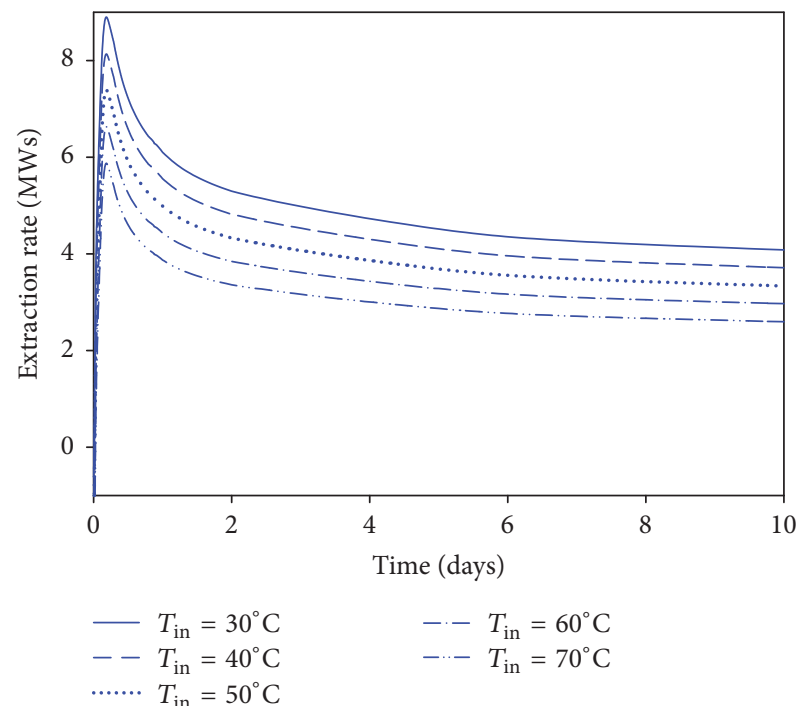

(b)

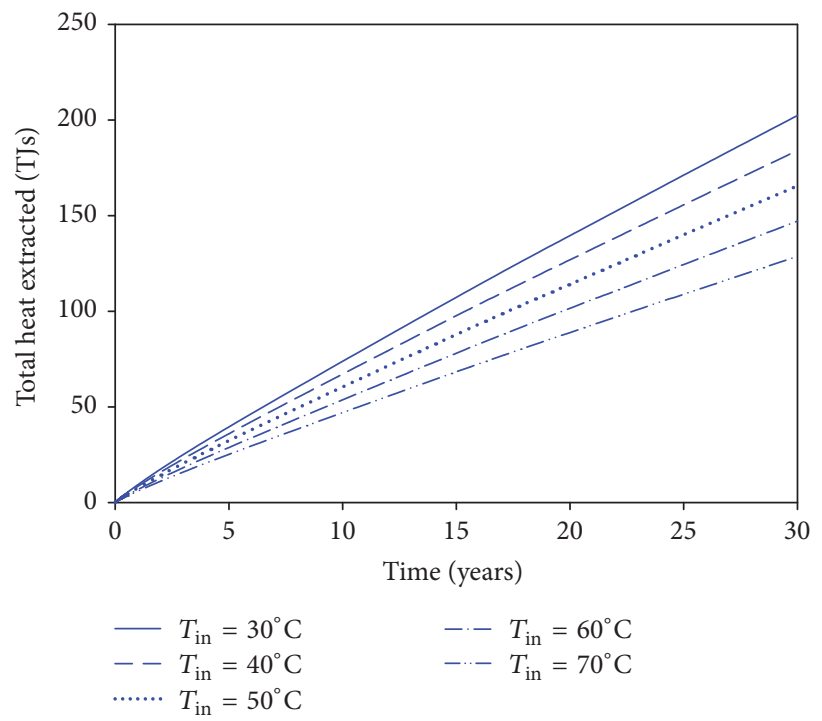

(c)

FIGURE 8: Thermal power and total heat extracted for different injection temperatures: thermal power (a) for large time and (b) for short time and (c) total heat extracted.

that can be made based on our numerical results are as follows:

(1) The difference in the output temperature predicted from the proposed model and TOUGH 2 is very small, less than $4^{\circ} \mathrm{C}$ in the present numerical study, and thus can be used to approximately predict the heat extraction from the closed-loop geothermal system.

(2) The injection rate plays the dominant role in affecting the output performance; although it can increase the thermal power, the reduced temperature as a result of high flow rate compromises its production performance.
(3) Higher injection temperature produces larger output temperature but decreases the total heat extracted given a specific time.

(4) The output performance of geothermal reservoir is insensitive to fluid viscosity.

(5) There exists a critical point that indicates if the fluid above and below this point releases heat into or absorbs heat from surrounding formation.

(6) This approximation model proposed in this work runs in terms of seconds on a personal notebook computer and thus provides an efficient tool for reservoir optimization. 


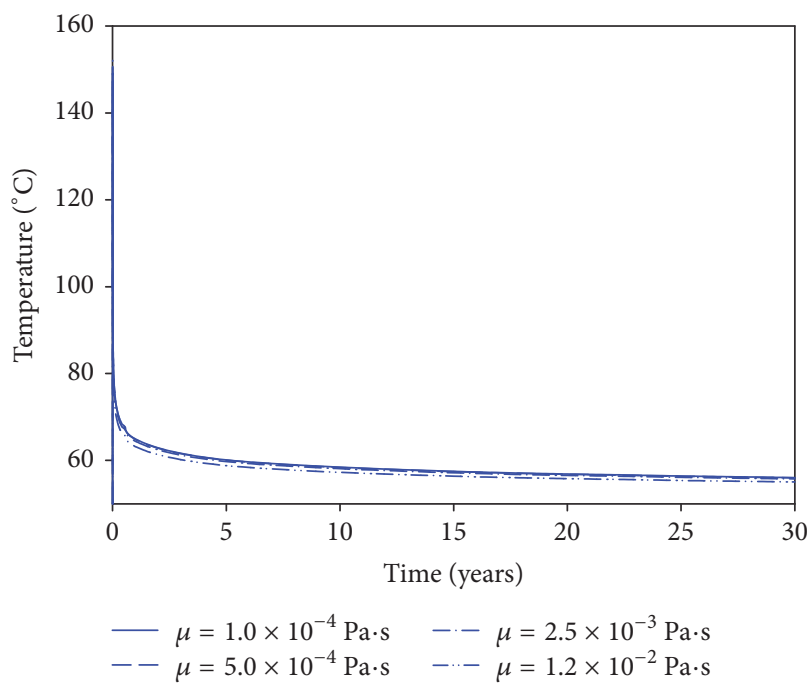

(a)

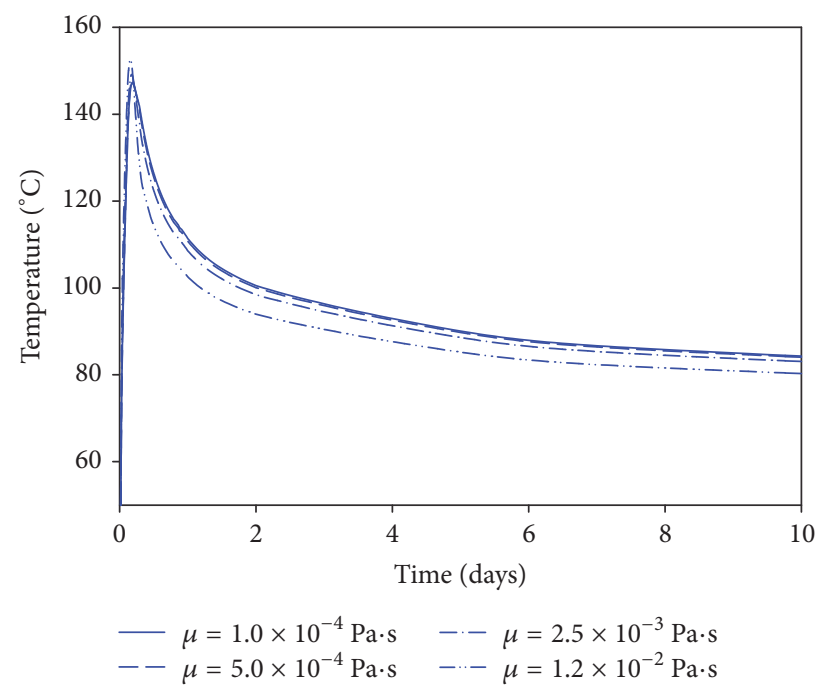

(b)

FIGURE 9: Variation with time of output temperature of the production well under different viscosities $\mu$ : (a) for large time period and (b) for short time period.

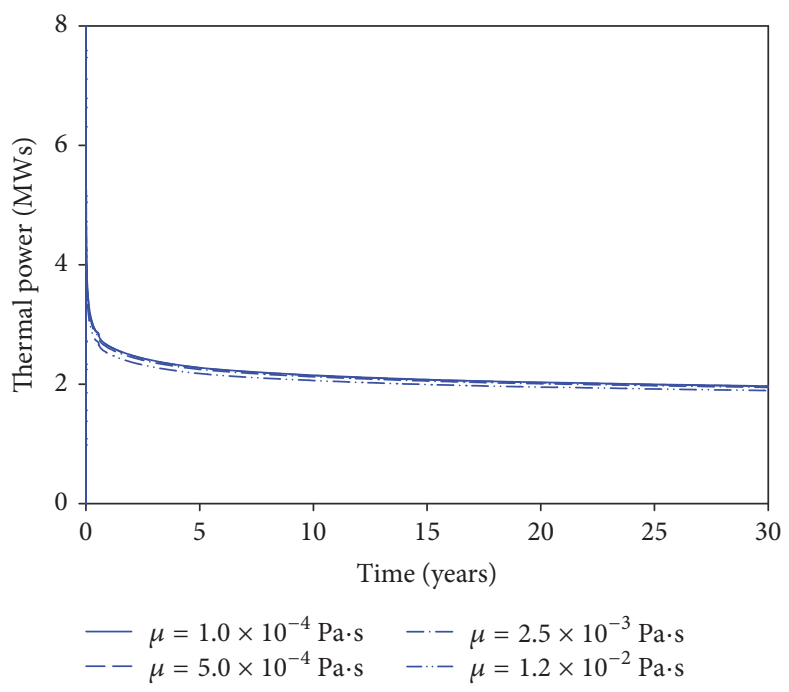

(a)

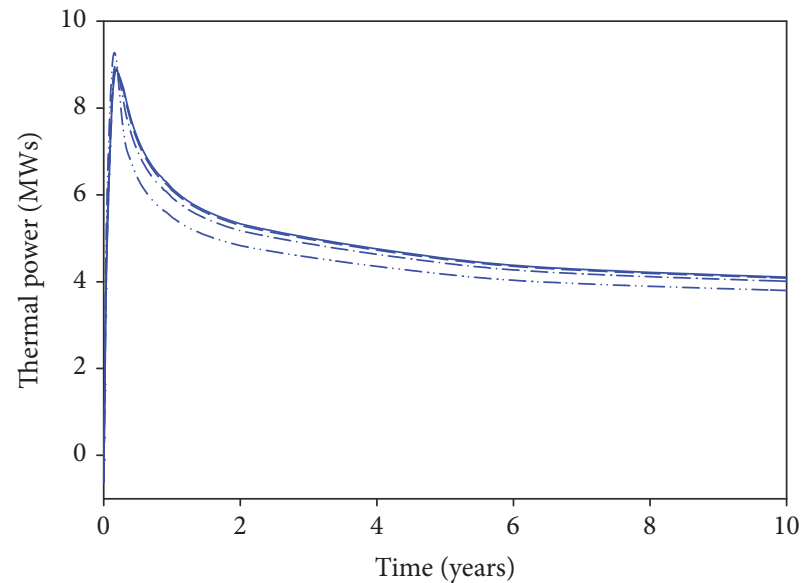

$-\mu=1.0 \times 10^{-4} \mathrm{~Pa} \cdot \mathrm{s} \quad--\mu=2.5 \times 10^{-3} \mathrm{~Pa} \cdot \mathrm{s}$$$
--\mu=5.0 \times 10^{-4} \mathrm{~Pa} \cdot \mathrm{s} \quad-\cdots \mu=1.2 \times 10^{-2} \mathrm{~Pa} \cdot \mathrm{s}
$$

(b)

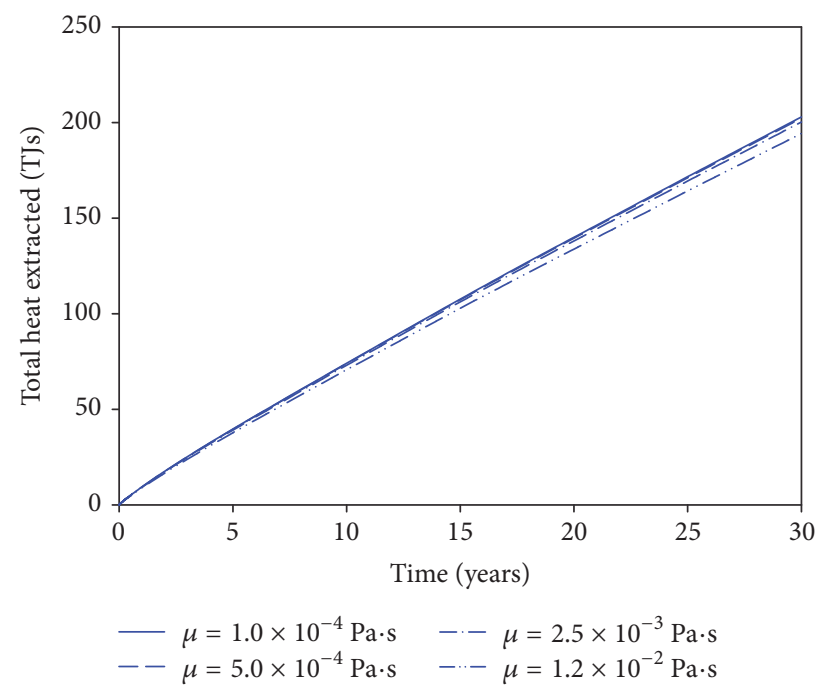

(c)

FIGURE 10: Thermal power and total heat extracted for different fluid viscosities: thermal power (a) for large time and (b) for short time and (c) total heat extracted. 


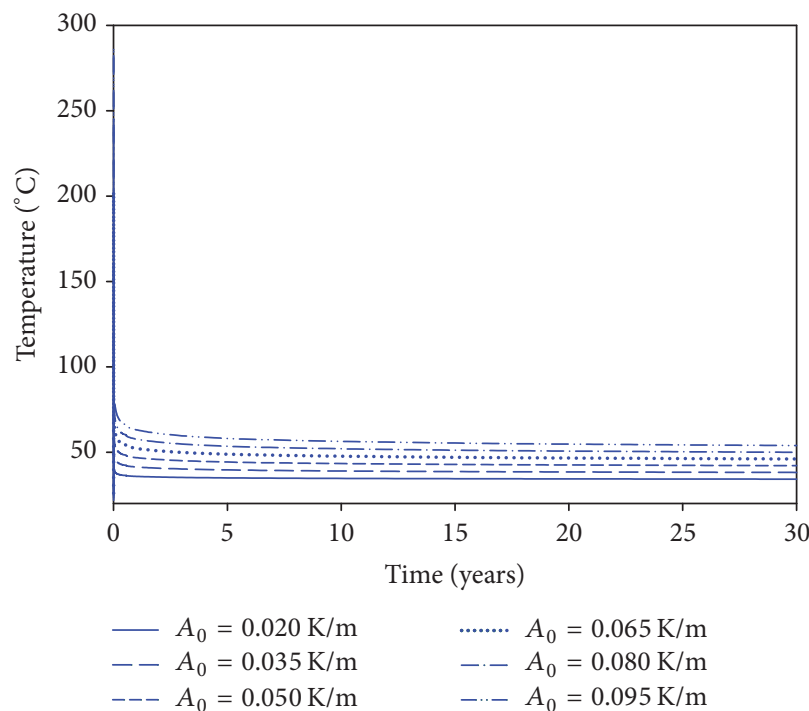

(a)

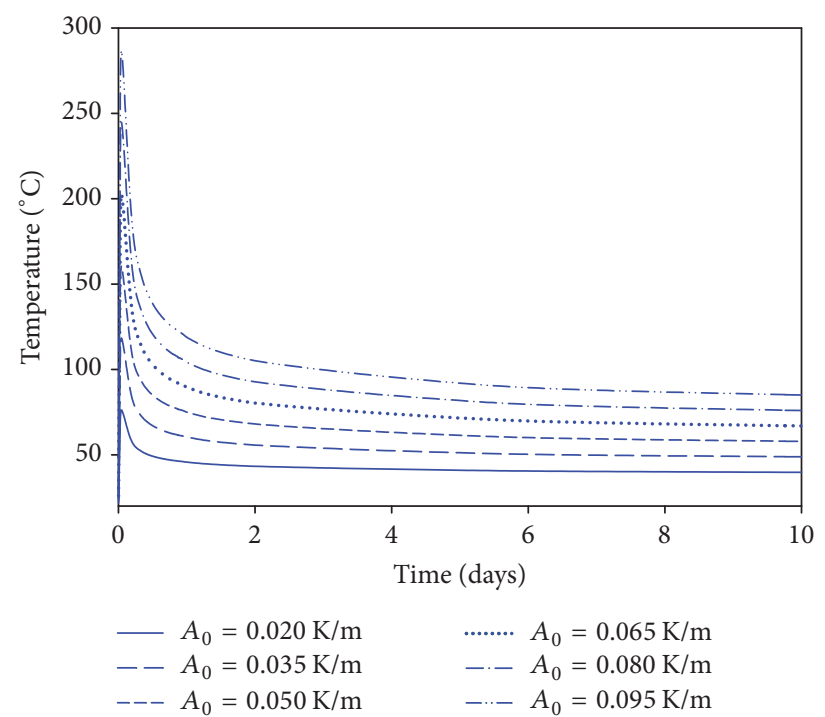

(b)

FIGURE 11: Variation with time of output temperature of the production well under different geothermal gradient $A_{0}$ : (a) for large time period and (b) for short time period.

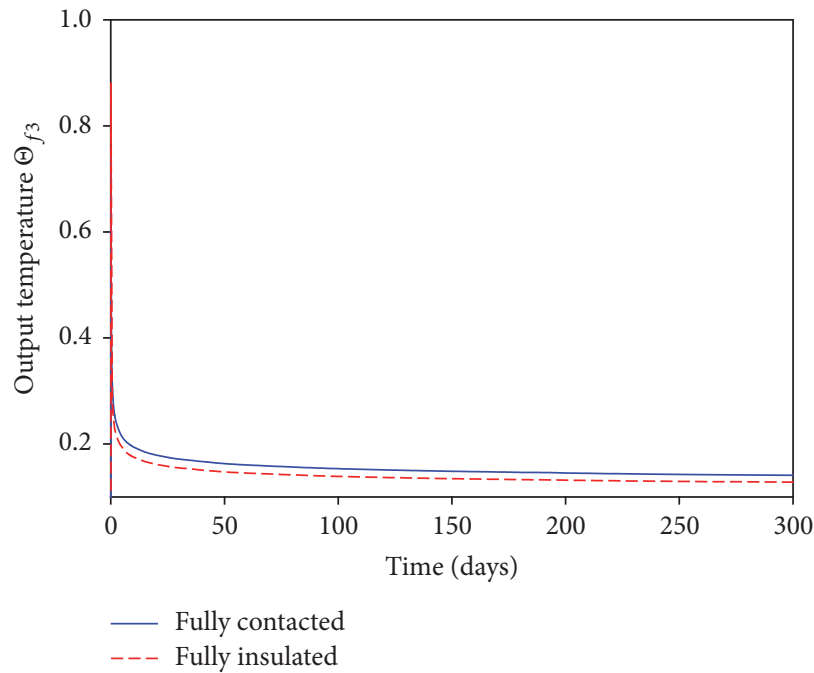

FIGURE 12: Production temperature under fully contacted and fully insulated conditions along the production well when $Q=0.05 \mathrm{~m}^{3} / \mathrm{s}$, $L_{1}=3500 \mathrm{~m}$, and $L_{2}=6000 \mathrm{~m}$.

\section{Conflicts of Interest}

The authors declare that there are no conflicts of interest regarding the publication of this paper.

\section{Acknowledgments}

The authors thank CSIRO for permission to publish the research outcomes. This work was supported by the Scientific Research Foundation of International Cooperation and Exchanges of Sichuan Province (Grant no. 2017HH0061), the National Natural Science Foundation of China (Grant no. 51604230), the China Postdoctoral Science Foundation
(Grant nos. 2016M600626 and 2017T100592), and the Fund of the State Key Laboratory of Oil and Gas Reservoir Geology and Exploitation of Southwest Petroleum University (Grant nos. G201604 and PLN201611).

\section{References}

[1] J. W. Lund and T. L. Boyd, "Direct utilization of geothermal energy 2015 worldwide review," Geothermics, vol. 60, pp. 66-93, 2016.

[2] A. Bahadori, S. Zendehboudi, and G. Zahedi, "RETRACTED: A review of geothermal energy resources in Australia: Current status and prospects," Renewable and Sustainable Energy Reviews, vol. 21, pp. 29-34, 2013. 
[3] J. M. Sharp Jr., "Energy and momentum transport model of the Ouachita Basin and its possible impact on formation of economic mineral deposits," Economic Geology, vol. 73, no. 6, pp. 1057-1068, 1978.

[4] J. Hecht-Méndez, M. De Paly, M. Beck, and P. Bayer, "Optimization of energy extraction for vertical closed-loop geothermal systems considering groundwater flow," Energy Conversion and Management, vol. 66, pp. 1-10, 2013.

[5] A. Casasso and R. Sethi, "Efficiency of closed loop geothermal heat pumps: A sensitivity analysis," Renewable Energy, vol. 62, pp. 737-746, 2014.

[6] B. Wu, X. Zhang, A. P. Bunger, and R. G. Jeffrey, "An efficient and accurate approach for studying the heat extraction from multiple recharge and discharge wells," in Effective and Sustainable Hydraulic Fracturing, A. Bunger, J. McLennan, and R. Jeffrey, Eds., p. 16, InTech, 2013.

[7] B. Wu, G. Zhang, X. Zhang, R. G. Jeffrey, J. Kear, and T. Zhao, "Semi-analytical model for a geothermal system considering the effect of areal flow between dipole wells on heat extraction," Energy, vol. 138, pp. 290-305, 2017.

[8] L. Eppelbaum, I. Kutasov, and A. Pilchin, Applied Geothermics, Lecture Notes in Earth System Sciences, Springer-Verlag, Berlin, Germany, 2014.

[9] H. Quick, J. Michael, U. Arslan, and H. Huber, "Geothermal application in low-enthalpy regions," Renewable Energy, vol. 49, pp. 133-136, 2013.

[10] B. Wu, X. Zhang, R. G. Jeffrey, and B. Wu, "A semi-analytic solution of a wellbore in a non-isothermal low-permeability porous medium under non-hydrostatic stresses," International Journal of Solids and Structures, vol. 49, no. 13, pp. 1472-1484, 2012.

[11] T. Ma, Q. Zhang, P. Chen, C. Yang, and J. Zhao, "Fracture pressure model for inclined wells in layered formations with anisotropic rock strengths," Journal of Petroleum Science and Engineering, vol. 149, pp. 393-408, 2017.

[12] T. Ma, B. Wu, J. Fu, Q. Zhang, and P. Chen, "Fracture pressure prediction for layered formations with anisotropic rock strengths," Journal of Natural Gas Science and Engineering, vol. 38, pp. 485-503, 2017.

[13] E. C. Bullard, "The time necessary for a bore hole to attain temperature equilibrium," Geophysical Journal International, vol. 5, pp. 127-130, 1947.

[14] J. T. Moss and P. D. White, "How to calculate temperature profiles in a water injection well," The Oil and Gas Journal, vol. 57, pp. 174-177, 1959.

[15] H. S. Carslaw and J. C. Jaeger, Conduction of Heat in Solids, The Clarendon Press, Oxford, UK, 1st edition, 1946.

[16] P. Eskilson, Thermal analysis of heat extraction boreholes [Ph.D. thesis], University of Lund, Lund, Sweden, 1987.

[17] H. Y. Zeng, N. R. Diao, and Z. H. Fang, "A finite line-source model for boreholes in geothermal heat exchangers," Heat Transfer-Asian Research, vol. 31, no. 7, pp. 558-567, 2002.

[18] M. G. Sutton, D. W. Nutter, and R. J. Couvillion, "A ground resistance for vertical bore heat exchangers with groundwater flow," Journal of Energy Resources Technology, Transactions of the ASME, vol. 125, no. 3, pp. 183-189, 2003.

[19] T. V. Bandos, Á. Montero, E. Fernández et al., "Finite linesource model for borehole heat exchangers: effect of vertical temperature variations," Geothermics, vol. 38, no. 2, pp. 263-270, 2009.
[20] A. Michopoulos and N. Kyriakis, "Predicting the fluid temperature at the exit of the vertical ground heat exchangers," Applied Energy, vol. 86, no. 10, pp. 2065-2070, 2009.

[21] N. Molina-Giraldo, P. Blum, K. Zhu, P. Bayer, and Z. Fang, "A moving finite line source model to simulate borehole heat exchangers with groundwater advection," International Journal of Thermal Sciences, vol. 50, no. 12, pp. 2506-2513, 2011.

[22] J. A. Rivera, P. Blum, and P. Bayer, "Influence of spatially variable ground heat flux on closed-loop geothermal systems: Line source model with nonhomogeneous Cauchy-type top boundary conditions," Applied Energy, vol. 180, pp. 572-585, 2016.

[23] G. Zhou, Y. Zhou, and D. Zhang, "Analytical solutions for two pile foundation heat exchanger models in a double-layered ground," Energy, vol. 112, pp. 655-668, 2016.

[24] H. Ramey, "Wellbore heat transmission," Journal of Petroleum Technology, vol. 14, no. 04, pp. 427-435, 2013.

[25] W. L. Dowdle and W. M. Cobb, "Static formation temperature from well logs - an empirical method," JPT, Journal of Petroleum Technology, vol. 27, pp. 1326-1330, 1975.

[26] M. Edwardson, H. Girner, H. Parkison, C. Williams, and C. Matthews, "Calculation of formation temperature disturbances caused by mud circulation," Journal of Petroleum Technology, vol. 14, no. 04, pp. 416-426, 2013.

[27] A. Tragesser, P. B. Crawford, and H. R. Crawford, "A method for calculating circulating temperatures," Journal of Petroleum Technology, vol. 19, no. 11, pp. 1507-1512, 2013.

[28] L. Raymond, "Temperature distribution in a circulating drilling fluid," Journal of Petroleum Technology, vol. 21, no. 03, pp. 333341, 2013.

[29] C. S. Holmes and S. C. Swift, "Calculation of circulating mud temperatures," Journal of Petroleum Technology, vol. 22, no. 6, pp. 670-674, 1970.

[30] H. Keller, E. Couch, and P. Berry, "Temperature distribution in circulating mud columns," Society of Petroleum Engineers Journal, vol. 13, no. 1, pp. 23-30, 2013.

[31] A. García, E. Santoyo, G. Espinosa, I. Hernández, and H. Gutiérrez, "Estimation of temperatures in geothermal wells during circulation and shut-in in the presence of lost circulation," Transport in Porous Media, vol. 33, no. 1-2, pp. 103-127, 1998.

[32] G. Espinosa-Paredes, A. Garcia, E. Santoyo, and I. Hernandez, "TEMLOPI/V.2: A computer program for estimation of fully transient temperatures in geothermal wells during circulation and shut-in," Computers and Geosciences, vol. 27, no. 3, pp. 327344, 2001.

[33] S. Fomin, T. Hashida, V. Chugunov, and A. V. Kuznetsov, "A borehole temperature during drilling in a fractured rock formation," International Journal of Heat and Mass Transfer, vol. 48, no. 2, pp. 385-394, 2005.

[34] B. Izgec, C. S. Kabir, D. Zhu, and A. R. Hasan, "Transient fluid and heat flow modeling in coupled wellbore/reservoir systems," SPE Reservoir Evaluation and Engineering, vol. 10, no. 3, pp. 294301, 2007.

[35] B. Wu, X. Zhang, and R. G. Jeffrey, "A model for downhole fluid and rock temperature prediction during circulation," Geothermics, vol. 50, pp. 202-212, 2014.

[36] K. L. Kipp, P. A. Hsieh, and S. R. Charlton, "Transport Simulator: HYDROTHERM - Version 3,” U.S. Geological Survey, 2008.

[37] K. Pruess, C. Oldenburg, and G. Moridis, “TOUGH2 User's Guide Version 2," Tech. Rep. LBNL-43134, Lawrence Berkeley National Laboratory, Berkeley, Calif, USA, 1999. 
[38] N. Böttcher, N. Watanabe, U. J. Görke, and O. Kolditz, Modeling I: Geothermal Processes in Fractured Porous Media, Springer, 2017.

[39] O. Kolditz, A. Habbar, R. Kaiser et al., ROCKFLOW users manual release 3.5. Institute of fluid mechanics and computer applications in civil engineering, University of Hannover, 2001.

[40] H.-J. G. Diersch, D. Bauer, W. Heidemann, W. Rühaak, and P. Schätzl, "Finite element modeling of borehole heat exchanger systems. Part 2. Numerical simulation," Computers and Geosciences, vol. 37, no. 8, pp. 1136-1147, 2011.

[41] H.-J. G. Diersch, FEFLOW: Finite Element Modeling of Flow, Mass and Heat Transport in Porous and Fractured Media, Springer, Berlin, Germany, 2014.

[42] N. Tenma, K. Yasukawa, and G. Zyvoloski, "Model study of the thermal storage system by FEHM code," Geothermics, vol. 32, no. 4, pp. 603-607, 2003.

[43] K. J. Bakhsh, M. Nakagawa, M. Arshad, and L. Dunnington, "Modeling thermal breakthrough in sedimentary geothermal system," in Proceedings of the 41st Workshop on Geothermal Reservoir Engineering Stanford University, pp. 22-24, Stanford, Calif, USA, 2016.

[44] Schlumberger, "Eclipse, reference manual 2008," Tech. Rep., Schlumberger Information Solutions, Business Development Central and Eastern Europe, Hannover, Germany, 2008.

[45] V. Hamm and B. Bazargan Sabet, "Modelling of fluid flow and heat transfer to assess the geothermal potential of a flooded coal mine in Lorraine, France," Geothermics, vol. 39, no. 2, pp. 177186, 2010.

[46] Y. Ding, "Using boundary integral methods to couple a semianalytical reservoir flow model and a wellbore flow model," in Proceedings of the 15th Symposium on Reservoir Simulation, pp. 195-205, February 1999.

[47] A. Ghassemi, S. Tarasovs, and A. H.-D. Cheng, "An integral equation solution for three-dimensional heat extraction from planar fracture in hot dry rock," International Journal for Numerical and Analytical Methods in Geomechanics, vol. 27, no. 12, pp. 989-1004, 2003.

[48] D. Kumar and M. Gutierrez, "Three-dimensional heat flow model for enhanced geothermal systems using boundary element method," in Proceedings of the 38th Workshop on Geothermal Reservoir Engineering Stanford University, Stanford, California, February 2013.

[49] M. W. McClure and R. N. Horne, "An investigation of stimulation mechanisms in Enhanced Geothermal Systems," International Journal of Rock Mechanics and Mining Sciences, vol. 72, pp. 242-260, 2014.

[50] L. M. Jiji, Heat Conduction, Springer, Berlin, Germany, 3rd edition, 2009.

[51] G. Willhite, "Over-all heat transfer coefficients in steam and hot water injection wells," Journal of Petroleum Technology, vol. 19, no. 05, pp. 607-615, 2013.

[52] V. Gnielinski, "New equations for heat and mass transfer in turbulent pipe and channel flow," in Proceedings of the International Chemical Engineering 16, vol. 16, pp. 359-368, 1976.

[53] L. D’Amore, G. Laccetti, and A. Murli, "An implementation of a Fourier series method for the numerical inversion of the Laplace transform," ACM Transactions on Mathematical Software, vol. 25, no. 3, pp. 279-305, 1999. 

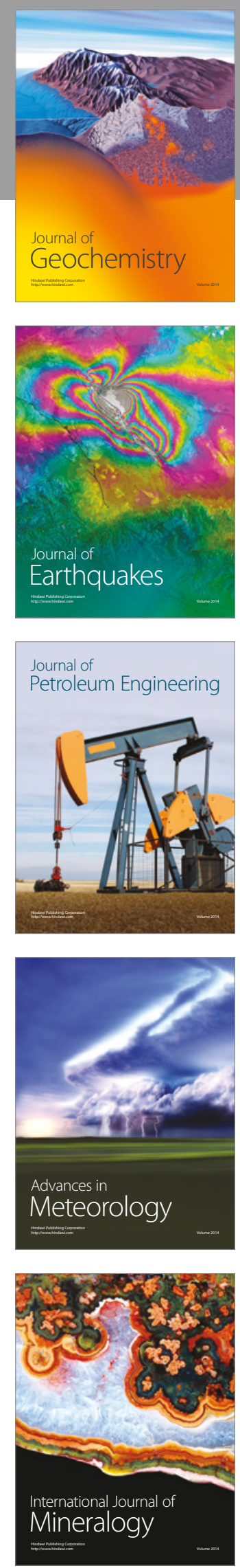
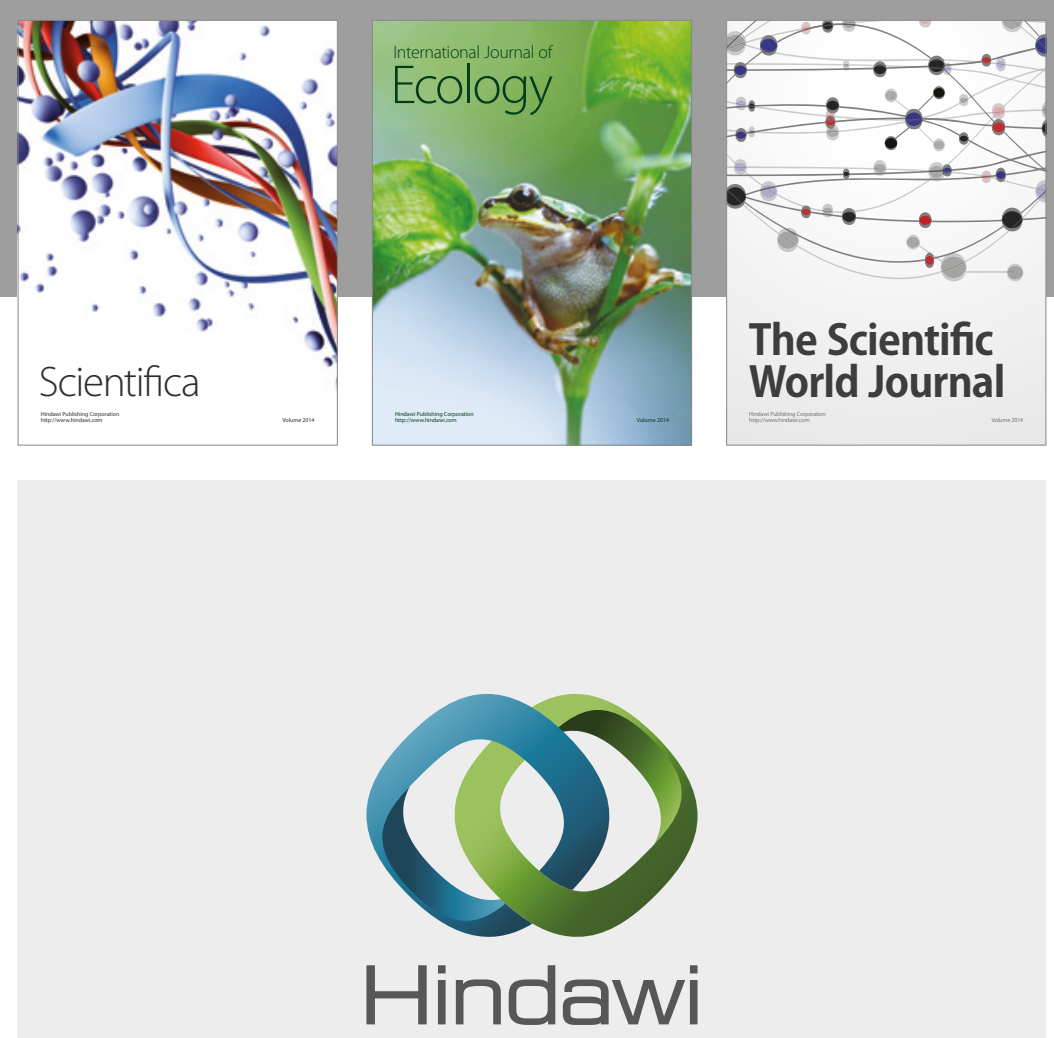

Submit your manuscripts at

https://www.hindawi.com
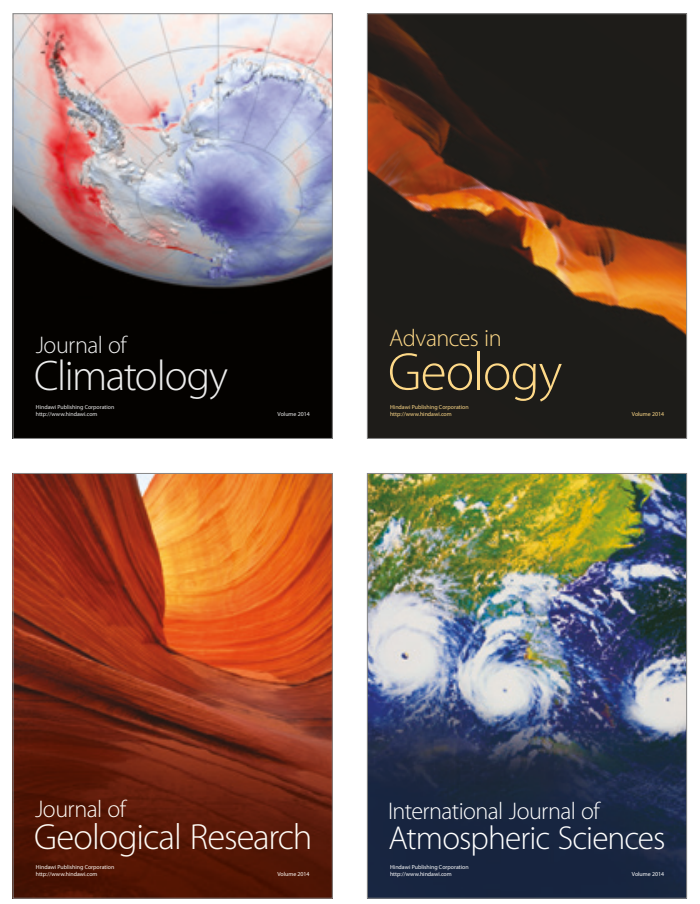

The Scientific

World Journal
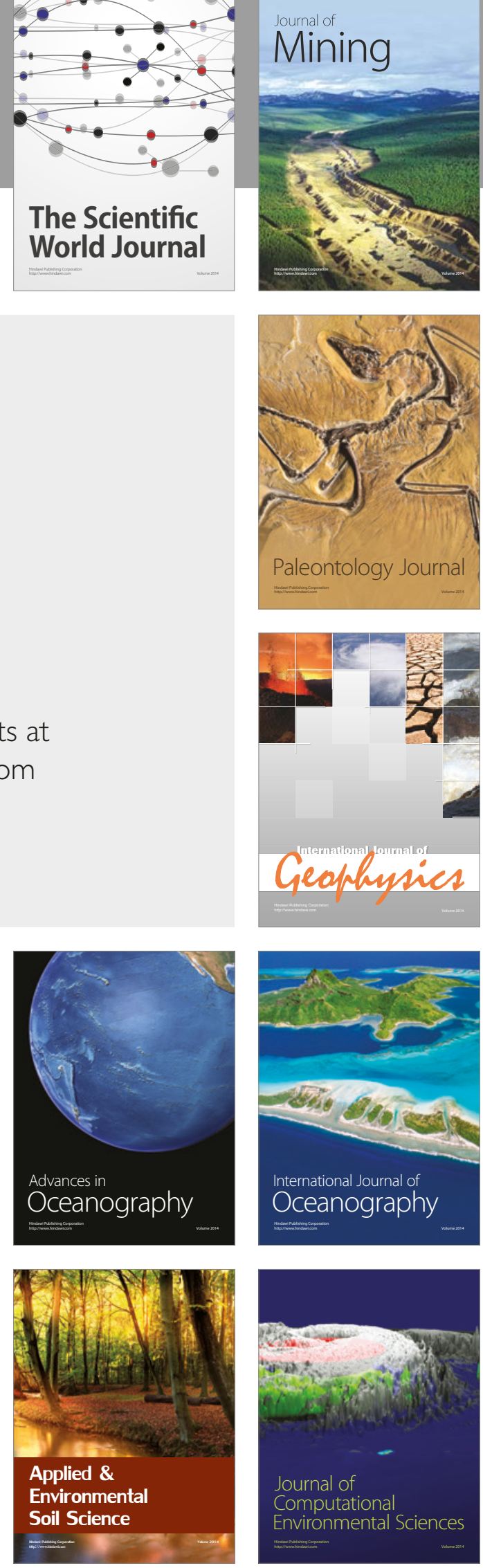